Check for updates

Cite this: J. Mater. Chem. C, 2017, 5, 7784

\section{Dual emission and multi-stimuli-response in iridium(III) complexes with aggregation-induced enhanced emission: applications for quantitative $\mathrm{CO}_{2}$ detection $\dagger$}

\author{
Clàudia Climent, $\ddagger^{\mathrm{a}}$ Parvej Alam, $\ddagger^{\mathrm{b}}$ Sheik Saleem Pasha, ${ }^{\mathrm{b}}$ Gurpreet Kaur, ${ }^{\mathrm{C}}$ \\ Angshuman Roy Choudhury, ${ }^{c}$ Inamur Rahaman Laskar, (D) *b Pere Alemany (D) *a \\ and David Casanova (D) *de
}

\begin{abstract}
Four new Ir(III) complexes with the general formula $\left[\mid r H C l\left(C^{\wedge} N\right)\left(\mathrm{PPh}_{3}\right)_{2}\right]$ containing different conjugated Schiff base ligands $\left(C^{\wedge} N\right)$ have been synthesized and characterized by ${ }^{1} \mathrm{H},{ }^{13} \mathrm{C}$, and ${ }^{31} \mathrm{P} N M R$, HRMS, and IR spectra and one of them by single crystal X-ray diffraction. Their photophysical properties in solution and in the solid state have been analyzed and three main practical results have been obtained: (i) a dual fluorescent and phosphorescent emissive complex in solution, (ii) successful acid/base sensing in the solid state and (iii) quantitative $\mathrm{CO}_{2}$ detection. Quantum chemical calculations have been employed to assign the character of the lowest excited states. A plausible explanation for the observed aggregation induced enhanced emission (AIEE) is given, based on the restriction of intramolecular motions due to the effect of intermolecular $\mathrm{C}-\mathrm{H} \cdots \pi$ and $\mathrm{C}-\mathrm{H} \cdots \mathrm{Cl}$ type interactions upon aggregation.
\end{abstract}

Received 22nd May 2017, Accepted 6th July 2017

DOI: $10.1039 / \mathrm{c} 7 \mathrm{tc0} 2250 \mathrm{f}$

rsc.li/materials-c makes them appealing for applications such as solid state lighting, where the luminescent complexes are present in aggregated forms such as solids or thin films. A key step in developing new materials based on the AIEE effect is to understand its origin at a fundamental level. The mechanism behind AIEE is, however, still under debate ${ }^{29-32}$ since many types of different systems, ranging from purely organic molecules to organometallic complexes, sometimes containing highly flexible parts, but in other cases quite rigid, have been identified as AIEE active compounds. In order to understand the origin of this photophysical phenomenon and identify the key parameters controlling its efficiency to optimize the implementation of AIEE materials in technological applications, it is necessary to combine experimental investigations with theoretical and computational studies.

In the present work, we report the complete synthesis of four novel Ir(III) complexes (1-4) by aliphatic $\mathrm{C}-\mathrm{H}$ activation of a Schiff base ligand, in line with recent reports on the synthesis of new $\operatorname{Ir}(\mathrm{III})^{11,19-21,33-37}$ and $\mathrm{Pt}(\mathrm{II})^{38}$ luminescent complexes. Using both experimental characterization techniques and $a b$ initio quantum chemical calculations we explore the photophysical properties of the synthesized compounds. In particular, complex 4 has been found to exhibit dual fluorescence and phosphorescence emission with the particularity that the fluorescent emission band is solvatochromic. This property is indeed very suitable for the development of Ir(III) probes, ${ }^{39}$ in which switching of the luminescence by external stimuli is essential. 
In the literature, there are several examples of dual phosphorescent Ir(III) complexes, ${ }^{40-47}$ but dual fluorescent and phosphorescent Ir(III) complexes are still scarce. ${ }^{48-51}$ To the best of our knowledge, the Ir(III) complex that we report herein is the first example of facile emission tuning between a singlet and a triplet state by just varying the solvent's polarity. This certainly opens a whole new range of possibilities for the application of $\operatorname{Ir}($ III) complexes as luminescent probes.

The capability of the synthesized complexes as acid-base sensors in the solid state and the potential use of complex 4 in the quantitative detection of $\mathrm{CO}_{2}$ has also been explored. Due to the well-known harmful effects that high concentrations of $\mathrm{CO}_{2}$ have on human beings, the development of molecular sensors for its quantitative detection is nowadays an intense research field. ${ }^{52-58}$ Current detection techniques ${ }^{59,60}$ based on electrochemical (EC), infrared (IR), or gas chromatography-mass spectroscopy (GC-MS) methods, or field-effect transistors are quite costly, and efficient molecular sensors based on AIEE materials could represent a real breakthrough in this area.

\section{Materials, methods and characterization}

\subsection{Materials}

Ir(III) chloride hydrate, triphenylphosphine, pyridine-2-amine, pyrimidine-2-amine, 5-methylpyridine-2-amine, benzaldehyde, triphenylamine, phosphorous oxychloride, dimethyl formamide and 2-ethoxyethanol were purchased from the Sigma Aldrich Chemical Company Ltd. All spectroscopic grade solvents: dichloromethane (DCM), methanol (MeOH), benzene, 1,4-dioxane, ethyl acetate, chloroform $\left(\mathrm{CHCl}_{3}\right)$, tetrahydrofuran (THF), acetonitrile (ACN), dimethylformamide (DMF) and dimethylsulphoxide (DMSO) were procured from the Merck Company.

\subsection{Synthesis}

2.2.1 Syntheses of Schiff bases. All four Schiff bases were synthesized using the well-known condensation method. In this case, benzaldehyde $(5.30 \mathrm{mmol})$ was added respectively to stirred solutions of pyridine-2-amine/pyrimidine-2-amine/ 5 -methylpyridine-2-amine $(5.30 \mathrm{mmol})$ in ethanol $(20 \mathrm{ml})$ followed by a catalytic amount of acetic acid and refluxed for 12 hours. The reaction mixture was evaporated under vacuum and used without further purification. The fourth Schiff base compound was prepared by following a similar route as described above where the reactants taken for the condensation reaction are 4-(diphenylamino)benzaldehyde and pyridimine 2-amine.

2.2.2 Syntheses of complexes 1-4. All four complexes were synthesized using the previous procedure reported by our group, ${ }^{35,36}$ where to a stirred solution of $\operatorname{IrCl}_{3} \cdot 3 \mathrm{H}_{2} \mathrm{O}(0.5025 \mathrm{mmol})$ in 2-ethoxyethanol $(6 \mathrm{ml})$, triphenylphosphine $(1.507 \mathrm{mmol})$ was added and the reaction mixture was refluxed at $130{ }^{\circ} \mathrm{C}$ for 4 hours. Then, the crude reaction mass of the respective Schiff bases (2.0 $\mathrm{mmol}$ ) was added to the reaction mixture, which was further refluxed for 3 hours and afterwards brought to room temperature. The resulting solid mass was triturated and washed with diethyl ether followed by ethanol for several times to obtain a solid (60-70\%) of 1-4 that was further purified through recrystallization from a mixture of DCM and hexane $(1: 1)$. X-ray quality single crystals could only be obtained for complex 2. Single crystal X-ray diffraction (SCXRD) revealed that the one-pot reaction of $\operatorname{Ir}(\mathrm{III})$ chloride and the triphenylphosphine mixture with the Schiff base resulted in a structure in which the imine $\mathrm{C}-\mathrm{H}$ position was activated by $\operatorname{Ir}(\mathrm{III})$.

\subsection{Characterization}

${ }^{1} \mathrm{H},{ }^{13} \mathrm{C}$ and ${ }^{31} \mathrm{P}$ NMR spectra were recorded in a $400 \mathrm{MHz}$ Bruker spectrometer using $\mathrm{CDCl}_{3}$ as a solvent. Tetramethylsilane (TMS, $\delta=0$ for ${ }^{1} \mathrm{H}$ and ${ }^{13} \mathrm{C}$ NMR) and phosphoric acid $\left(\mathrm{H}_{3} \mathrm{PO}_{4}, \delta=0\right.$ for $\left.{ }^{31} \mathrm{P} \mathrm{NMR}\right)$ were used as internal standards. UV-VIS absorption spectra were recorded in a Simadzu Spectrophotometer (model UV-1800). The photoluminescence (PL) spectra were recorded on a Fluoromax-4 (0406C-0809) spectrofluorophotometer. The steady state photoluminescence spectra were recorded on a Spectrofluorometer FLS920-s Edinburgh. The quantum efficiency (QE) in solution for 1-4 has been measured with respect to coumarin 153 (in degassed ethanol, $\mathrm{QE}=0.38$, excitation 400-420 nm). High-resolution MS (HRMS) experiments were carried out with a (TOF MS ES+1.38 eV) VG Analytical (70-S) spectrometer and a Q-Tof micro mass spectrometer. Infrared spectra were recorded with an FTIR Shimadzu (IR prestige-21) spectrometer. All the reactions were performed under a nitrogen atmosphere and the progress of the reaction was monitored using thin-layer chromatography (TLC) plates (pre-coated with $0.20 \mathrm{~mm}$ silica gel).

Lifetime data have been acquired with time correlated single photon counting (TCSPC) instruments, suitable for a ns-ps time range and nano LEDs with a $375 \mathrm{~nm}$ (average pulse width of $60.4 \mathrm{ps}$ ) and $405 \mathrm{~nm}$ (average pulse width of $56.9 \mathrm{ps}$ ) excitation source at room temperature. The solid-state quantum yield of the powder samples was measured using a calibrated integrating sphere in a Gemini spectrophotometer (Gemini 180). The emission and absorption spectra of the complexes were recorded after purging the sample with $\mathrm{N}_{2}$ gas.

The highly shielded ${ }^{1} \mathrm{HNMR}$ signal in the range of -14.39 to -14.53 ppm indicates the presence of hydride ( $\mathrm{Ir}-\mathrm{H})$ in the complexes. This finding is further supported by the stretching frequency at $2128-2176 \mathrm{~cm}^{-1}$ recorded by FTIR and the value computed using density functional theory (DFT) based methods at $\sim 2210 \mathrm{~cm}^{-1}$ for all the complexes. The IR stretching frequency of $\mathrm{C}=\mathrm{N}$ in the Schiff base ligands appears within the $1579-1610 \mathrm{~cm}^{-1}$ range and the computed DFT frequencies have the same order of magnitude (Table S8, ESI $\dagger$ ). A ${ }^{31}$ P NMR signal is observed in the range of 4.34-6.39 ppm. From the HRMS data, the major fragmented peak appears as $[\mathbf{M}+\mathbf{H}]^{+}$at $m / z$ in the range of 936.2476-1102.2661.

Complex 1. ${ }^{1} \mathrm{H}$ NMR (400 MHz, $\left.\mathrm{CDCl}_{3}\right) \delta 8.61-8.27(\mathrm{~m}, 1 \mathrm{H})$, $7.84(\mathrm{~d}, J=7.6 \mathrm{~Hz}, 1 \mathrm{H}), 7.44$ (dt, $J=10.9,5.4 \mathrm{~Hz}, 4 \mathrm{H}), 7.12$ $(\mathrm{dt}, J=26.6,7.2 \mathrm{~Hz}, 6 \mathrm{H}), 6.97(\mathrm{t}, J=7.2 \mathrm{~Hz}, 1 \mathrm{H}), 6.72(\mathrm{t}, J=$ $7.4 \mathrm{~Hz}, 1 \mathrm{H}), 6.46-6.26(\mathrm{~m}, 1 \mathrm{H}),-14.47(\mathrm{t}, J=16.0 \mathrm{~Hz}, 1 \mathrm{H})$; ${ }^{31} \mathrm{P} \mathrm{NMR}\left(162 \mathrm{MHz}, \mathrm{CDCl}_{3}\right) \delta 5.69 ;{ }^{13} \mathrm{C} \mathrm{NMR}\left(101 \mathrm{MHz}, \mathrm{CDCl}_{3}\right) \delta$ 176.13, 158.13, 158.13, 155.44, 144.27, 134.09, 134.04, 133.99, 
$130.95,130.68,130.40,130.09,129.59,128.68,128.57,128.45$, 127.54, 127.49, 127.44, 126.11, 113.19; IR (KBr, $\left.\mathrm{cm}^{-1}\right): 2151$ $\left(\mathrm{m}, \nu_{\mathrm{Ir}-\mathrm{H}}\right)$ and 1580 and $1542\left(\mathrm{~m}, \nu_{\mathrm{C}=\mathrm{N}}\right)$; ESI-HRMS, calculated: $\left([\mathrm{M}+\mathrm{H}]^{+}\right), m / z$ 936.4581, found $\left([\mathbf{M}+\mathrm{H}]^{+}\right): m / z$ 936.2476. (Fig. S1, ESI $\dagger$ )

Complex 2. ${ }^{1} \mathrm{H}$ NMR $\left(400 \mathrm{MHz}, \mathrm{CDCl}_{3}\right) \delta 8.18(\mathrm{~d}, J=5.5 \mathrm{~Hz}$, $1 \mathrm{H}), 7.51(\mathrm{dd}, J=19.6,7.7 \mathrm{~Hz}, 4 \mathrm{H}), 7.37(\mathrm{ddd}, J=8.2,6.7,3.3 \mathrm{~Hz}$, $12 \mathrm{H}), 7.06$ (tt, $J=8.1,4.1 \mathrm{~Hz}, 18 \mathrm{H}), 6.89(\mathrm{t}, J=7.3 \mathrm{~Hz}, 2 \mathrm{H}), 6.66$ $(\mathrm{dd}, J=17.8,9.8 \mathrm{~Hz}, 2 \mathrm{H}), 6.52-6.22(\mathrm{~m}, 1 \mathrm{H}),-14.49(\mathrm{t}, J=$ $16.1 \mathrm{~Hz}, 1 \mathrm{H}) ;{ }^{31} \mathrm{P}$ NMR (162 $\left.\mathrm{MHz}, \mathrm{CDCl}_{3}\right) \delta 4.34 ;{ }^{13} \mathrm{C} \mathrm{NMR}$ $\left(101 \mathrm{MHz}, \mathrm{CDCl}_{3}\right) \delta 171.22,147.18,145.22,137.16,134.15$, 134.10, 134.04, 131.51, 131.24, 130.97, 129.34, 128.89, 127.37, 127.32, 127.28, 126.21, 117.81, 117.58; IR ( $\left.\mathrm{KBr}, \mathrm{cm}^{-1}\right): 2128$ $\left(\mathrm{m}, \nu_{\mathrm{Ir}-\mathrm{H}}\right), 1603\left(\mathrm{~m}, \nu_{\mathrm{C}=\mathrm{N}}\right)$; ESI-HRMS, calculated: $\left([\mathrm{M}+\mathrm{H}]^{+}\right)$, $m / z$ 935.2063, found $\left([\mathrm{M}+\mathrm{H}]^{+}\right): m / z 935.3567$ (Fig. S2, ESI $\dagger$ ).

Complex 3. ${ }^{1} \mathrm{H}$ NMR (400 MHz, $\left.\mathrm{CDCl}_{3}\right) \delta 7.81(\mathrm{~s}, 1 \mathrm{H}), 7.54$ $(\mathrm{d}, J=7.5 \mathrm{~Hz}, 2 \mathrm{H}), 7.48-7.36(\mathrm{~m}, 12 \mathrm{H}), 7.21-7.12(\mathrm{~m}, 7 \mathrm{H}), 7.12-$ $7.04(\mathrm{~m}, 11 \mathrm{H}), 6.98-6.88(\mathrm{~m}, 1 \mathrm{H}), 6.73(\mathrm{dd}, J=8.2,7.4 \mathrm{~Hz}, 2 \mathrm{H})$, $1.89(\mathrm{~s}, 3 \mathrm{H}),-14.48(\mathrm{t}, J=15.8 \mathrm{~Hz}, 1 \mathrm{H}) ;{ }^{31} \mathrm{P}$ NMR $(162 \mathrm{MHz}$, $\left.\mathrm{CDCl}_{3}\right) \delta 5.69 ;{ }^{13} \mathrm{C}$ NMR (101 MHz, $\left.\mathrm{CDCl}_{3}\right) \delta$ 169.12, 146.62, 145.41, 137.79, 134.14, 134.09, 134.03, 131.45, 131.18, 130.92, 129.22, 128.65, 127.28, 127.23, 127.18, 126.20, 117.41, 18.40. IR $\left(\mathrm{KBr}, \mathrm{cm}^{-1}\right): 2151\left(\mathrm{~m}, \nu_{\mathrm{Ir}-\mathrm{H}}\right), 1612$ and $1567\left(\mathrm{~m}, \nu_{\mathrm{C}=\mathrm{N}}\right)$ ESIHRMS, calculated: $\left([\mathrm{M}+\mathrm{H}]^{+}\right), m / z$ 949.2219, found $\left([\mathrm{M}+\mathrm{H}]^{+}\right)$: $m / z 949.2698$ (Fig. S3, ESI $\dagger$ ).

Complex 4. ${ }^{1} \mathrm{H}$ NMR $\left(400 \mathrm{MHz}, \mathrm{CDCl}_{3}\right) \delta 8.34(\mathrm{~d}, J=4.9 \mathrm{~Hz}$, $1 \mathrm{H}), 7.62(\mathrm{~d}, J=8.2 \mathrm{~Hz}, 2 \mathrm{H}), 7.51-7.35(\mathrm{~m}, 14 \mathrm{H}), 7.33-7.07$ $(\mathrm{m}, 22 \mathrm{H}), 7.01(\mathrm{dd}, J=15.9,7.7 \mathrm{~Hz}, 6 \mathrm{H}), 6.44(\mathrm{dd}, J=15.3$, $7.6 \mathrm{~Hz}, 3 \mathrm{H}),-14.43(\mathrm{t}, J=16.2 \mathrm{~Hz}, 1 \mathrm{H}) ;{ }^{31} \mathrm{P}$ NMR $(162 \mathrm{MHz}$, $\left.\mathrm{CDCl}_{3}\right) \delta 4.53 ;{ }^{13} \mathrm{C} \mathrm{NMR}\left(101 \mathrm{MHz}, \mathrm{CDCl}_{3}\right) \delta 171.39,148.62$, $147.48,147.27,139.47,137.14,134.31,134.25$, 134.20, 131.59, 131.32, 131.05, 129.36, 128.96, 127.40, 127.35, 127.30, 124.20, 122.69, 121.40, 117.49, 117.12; IR (KBr, $\left.\mathrm{cm}^{-1}\right): 2176$ (m, $\left.\nu_{\text {Ir-H }}\right)$, $1580\left(\mathrm{~m}, \nu_{\mathrm{C}=\mathrm{N}}\right)$; ESI-HRMS, calculated: $\left([\mathrm{M}+\mathrm{H}]^{+}\right), \mathrm{m} / \mathrm{z}$ 1102.2798, found $\left([\mathrm{M}+\mathrm{H}]^{+}\right): m / z 1102.2661$ (Fig. S4, ESI $\dagger$ ).

DEA. ${ }^{1} \mathrm{H}$ NMR (400 MHz, $\left.\mathrm{CDCl}_{3}\right) \delta 2.53(\mathrm{q}, J=7.2 \mathrm{~Hz}, 1 \mathrm{H})$, $0.98(\mathrm{t}, J=7.2 \mathrm{~Hz}, 2 \mathrm{H}) .{ }^{13} \mathrm{C}$ NMR (101 MHz, $\left.\mathrm{CDCl}_{3}\right) \delta 44.36$, 15.17 (Fig. S5, ESI $\dagger$ ).

DEA CO ${ }_{2}$ (a CIL). ${ }^{1} \mathrm{H}$ NMR $\left(400 \mathrm{MHz}, \mathrm{CDCl}_{3}\right) \delta 3.16(\mathrm{~s}, 1 \mathrm{H})$, $2.69(\mathrm{~s}, 2 \mathrm{H}), 1.10(\mathrm{~s}, 3 \mathrm{H}), 0.98(\mathrm{~s}, 1 \mathrm{H}) .{ }^{13} \mathrm{C} \mathrm{NMR}(101 \mathrm{MHz}$, $\left.\mathrm{CDCl}_{3}\right) \delta 42.17,40.63,13.98,12.67$ (Fig. S6, ESI $\dagger$ ).

Complex 1 + TFA. $1 \mathrm{H}$ NMR (400 MHz, CDCl3) $\delta 10.02(\mathrm{~s}, 1 \mathrm{H})$, $8.63(\mathrm{~d}, J=5.4 \mathrm{~Hz}, 5 \mathrm{H}), 8.26(\mathrm{~d}, J=5.5 \mathrm{~Hz}, 4 \mathrm{H}), 7.94(\mathrm{dd}, J=8.3$, $1.4 \mathrm{~Hz}, 2 \mathrm{H}), 7.79-7.48(\mathrm{~m}, 13 \mathrm{H}), 7.38(\mathrm{td}, J=6.9,3.4 \mathrm{~Hz}, 43 \mathrm{H})$, $7.32-7.22(\mathrm{~m}, 27 \mathrm{H}), 7.18(\mathrm{t}, J=7.4 \mathrm{~Hz}, 33 \mathrm{H}), 7.07-6.90(\mathrm{~m}, 8 \mathrm{H})$, 6.75 (s, 5H) (Fig. S7, ESI $\dagger$ ).

Complex 2 + TFA. ${ }^{1} \mathrm{H}$ NMR $\left(400 \mathrm{MHz}, \mathrm{CDCl}_{3}\right) \delta 13.56(\mathrm{~s}, 1 \mathrm{H})$, $8.12(\mathrm{~d}, J=5.5 \mathrm{~Hz}, 1 \mathrm{H}), 8.00(\mathrm{~d}, J=8.2 \mathrm{~Hz}, 1 \mathrm{H}), 7.76-7.66$ (m, 1H), 7.46-7.32 (m, 16H), $7.23(\mathrm{t}, J=7.4 \mathrm{~Hz}, 8 \mathrm{H}), 7.19-7.12$ $(\mathrm{m}, 10 \mathrm{H}), 6.89(\mathrm{dd}, J=8.3,7.6 \mathrm{~Hz}, 2 \mathrm{H}), 6.78(\mathrm{dd}, J=9.6,3.4 \mathrm{~Hz}$, $1 \mathrm{H}),-14.93$ (t, $J=14.3 \mathrm{~Hz}, 1 \mathrm{H}$ ) (Fig. S8, ESI $\dagger$ ).

Complex 3 + TFA. ${ }^{1} \mathrm{H}$ NMR $\left(400 \mathrm{MHz}, \mathrm{CDCl}_{3}\right) \delta 13.34(\mathrm{~s}, 1 \mathrm{H})$, $7.84(\mathrm{~d}, J=8.3 \mathrm{~Hz}, 1 \mathrm{H}), 7.71(\mathrm{~s}, 1 \mathrm{H}), 7.47(\mathrm{dd}, J=8.3,1.5 \mathrm{~Hz}, 2 \mathrm{H})$, $7.38(\mathrm{dt}, J=11.1,5.5 \mathrm{~Hz}, 14 \mathrm{H}), 7.23(\mathrm{t}, J=7.3 \mathrm{~Hz}, 7 \mathrm{H}), 7.15$ $(\mathrm{t}, J=7.4 \mathrm{~Hz}, 12 \mathrm{H}), 6.89(\mathrm{t}, J=7.9 \mathrm{~Hz}, 2 \mathrm{H}), 2.11(\mathrm{~s}, 3 \mathrm{H})-14.95$ (t, $J=14.0 \mathrm{~Hz}, 1 \mathrm{H})$ (Fig. S9, ESI $\dagger$ ).
Complex 4 + TFA. ${ }^{1} \mathrm{H}$ NMR $\left(400 \mathrm{MHz}, \mathrm{CDCl}_{3}\right) \delta 13.00(\mathrm{~s}, 1 \mathrm{H})$, $8.24(\mathrm{~d}, J=5.4 \mathrm{~Hz}, 1 \mathrm{H}), 7.90(\mathrm{~d}, J=8.2 \mathrm{~Hz}, 1 \mathrm{H}), 7.65(\mathrm{t}, J=7.4 \mathrm{~Hz}$, $1 \mathrm{H}), 7.38$ (ddd, $J=11.5,8.5,6.9 \mathrm{~Hz}, 2 \mathrm{H}), 7.31-7.24(\mathrm{~m}, 15 \mathrm{H})$, $7.20(\mathrm{t}, J=7.4 \mathrm{~Hz}, 21 \mathrm{H}), 7.05(\mathrm{~d}, J=7.6 \mathrm{~Hz}, 4 \mathrm{H}), 6.79-6.68$ $(\mathrm{t}, J=12.9 \mathrm{~Hz}, 1 \mathrm{H}), 6.37(\mathrm{~d}, J=42.1 \mathrm{~Hz}, 2 \mathrm{H}),-15.04(\mathrm{t}, J=$ $14.6 \mathrm{~Hz}, 1 \mathrm{H})$ (Fig. S10, ESI $\dagger$ ).

\subsection{Single crystal X-ray diffraction study}

Single crystal X-ray diffraction data for 2 were recorded on a Rigaku XtaLAB mini single crystal X-ray diffractometer equipped with a Mercury 375/M CCD detector and graphite monochromated $\mathrm{Mo}^{-} \mathrm{K}_{\alpha}$ radiation. The data set was collected at 100.0(1) K by using an Oxford cryosystem. The data were processed using Rigaku CrystalClear suite 2.0.61 The crystal structure was solved by using SHELXS2013 ${ }^{62}$ and refined using SHELXL2013, available within Olex2. ${ }^{63}$ All the hydrogen atoms have been fixed at their geometrically ideal position and have been refined isotropically using the riding model. Geometric calculations have been carried out using PARST. ${ }^{64}$

\subsection{Computational details}

Electronic structure calculations were performed within the DFT framework. Geometry optimizations of the ground state $\left(\mathrm{S}_{0}\right)$ and lowest triplet state $\left(\mathrm{T}_{1}\right)$ were carried out with the B3LYP hybrid functional, ${ }^{65}$ the double- $\zeta$ quality basis set consisting of Hay and Wadt's effective core potential (LANL2DZ) for the iridium atom and the standard all-electron 6-31G(d) basis set for all other elements. ${ }^{66-68}$ Optimized geometries were identified as true local minima with no imaginary frequencies within the harmonic approximation. Vertical transition energies at the $S_{0}$ and $\mathrm{T}_{1}$ geometries were computed via time-dependent DFT (TDDFT) with the same energy functional and basis set. The absorption spectra were simulated by convolution of Gaussian functions with a half-width at half maximum (HWHM) of $3500 \mathrm{~cm}^{-1}$. The vibrationally resolved emission spectra from $\mathrm{T}_{1}$ were simulated within the Franck-Condon approximation as described by Barone et al. ${ }^{69}$ and a HWHM of $650 \mathrm{~cm}^{-1}$ was used for the Gaussian convolution. All calculations were carried out considering isolated molecules in a vacuum, except for the optimization of the $S_{0}$ and intra-ligand charge transfer (ILCT) singlet state of complex 4, for which the IEF-PCM method ${ }^{70}$ was employed in order to account for equilibrium solvation. In addition, the CAM-B3LYP functional ${ }^{71}$ was used for the optimization of the ${ }^{1}$ ILCT state of $\mathbf{4}$ to account for the strong chargetransfer nature of this transition, not properly described by the B3LYP functional. ${ }^{72}$ Interactions between ACN molecules and Ir(III) complexes in the crystal structure were analyzed using two molecular models: (i) two Ir(III) complexes and the central ACN molecule and (ii) one Ir(III) complex with two ACN molecules interacting via both $\mathrm{PPh}_{3}$ ligands. Interaction energies between ACN molecules and Ir(III) complexes were computed by applying the standard counterpoise correction for the basis set superposition error $^{73}$ at the M06-2X/LANL2DZ,6-31G(d,p) level. ${ }^{74}$ The origin of the observed disorder for solvent molecules in the crystal structure was also investigated at the M06-2X/LANL2DZ, $6-31 G(d, p)$ level by carrying out a fixed rotation of the methyl 
group of one ACN molecule in the presence of the two neighboring interacting $\operatorname{Ir}(\mathrm{III})$ complexes with fixed geometries. Color coordinates for compounds 1-4 were calculated from the experimental emission spectra in the standard CIE $\left(2^{\circ}\right) 1931$ color space following the conventional procedure ${ }^{75}$ (ESI $\dagger$ ). All electronic structure calculations were performed using the Gaussian09 package. $^{76}$

\section{Results and discussion}

\subsection{Molecular and electronic structure}

All synthesized complexes have a single Ir(III) metal center in a distorted octahedral coordination environment. Complexes 1-4 contain two triphenylphosphine ligands $\left(\mathrm{PPh}_{3}\right)$ axially coordinated with the $\operatorname{Ir}($ III) atom, since our previous studies suggested that these highly mobile groups could be responsible for the observation of an enhanced emission in aggregated phases. ${ }^{20,37,77}$ The four coordination positions on the equatorial plane are occupied by the $\mathrm{N}$ and $\mathrm{C}$ atoms of a Schiff base bidentate ligand, a chloride, and a hydride ligand. The differences between the four synthesized complexes are in the Schiff base ligand (Scheme 1). Concretely, complex 1 contains a pyrimidine ring, while complexes $\mathbf{2}$ and $\mathbf{3}$ have pyridine and methylpyridine moieties instead, respectively. Complex 4 corresponds to the substitution of the Schiff base with a diphenylamine donor group.

The principal geometrical parameters describing the distorted octahedral environment of the $\operatorname{Ir}(\mathrm{III})$ atom in complex 2 are gathered in Table S2 (ESI $\dagger$ ). Optimized bond distances and angles for the ground state are in very good agreement with the X-ray molecular structure. A detailed discussion of the differences between the experimental and calculated geometries can be found in the ESI. $\dagger$

Next we analyze in detail the electronic structure of the synthesized compounds by means of their frontier occupied and virtual molecular orbitals (MOs). In the following we refer to the $z$-axis as the one in the P-Ir-P direction and the $x$-axis defined by the $\mathrm{C}-\mathrm{Ir}-\mathrm{Cl}$ direction. Fig. 1 depicts the MO energy

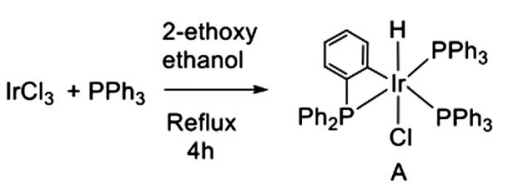
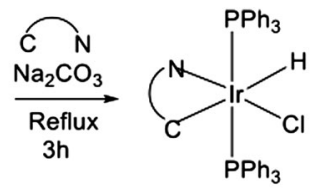

1-4

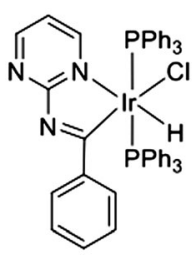

Complex 1

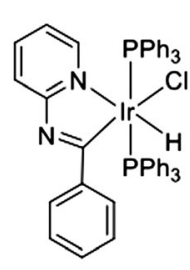

Complex 2

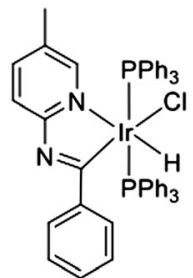

Complex 3

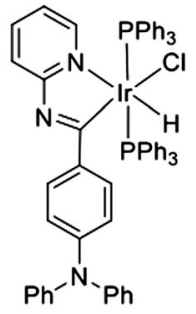

Complex 4

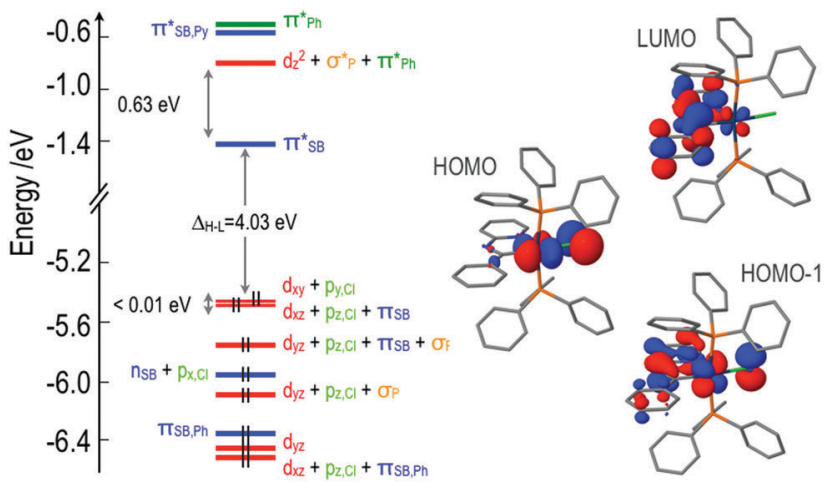

Fig. 1 Molecular orbital diagram of 2 at the ground state geometry optimized at the B3LYP/LANL2DZ,6-31G(d) level. Participation of fragment orbitals to the whole system's MOs is indicated by the following color code: red for d-block orbitals of the iridium atom; light green for $p$ orbitals of the chloride ligand; dark green for $\pi$ and $\pi^{\star}$ type orbitals of the phenyl rings of the phosphine ligands; blue for $n, \pi$ and $\pi^{\star}$-type orbitals of the Schiff base ligand and orange for $\sigma$-type orbitals of the phosphorous's lone pairs. Hydrogen atoms are omitted from the picture for the sake of clarity.

diagram for complex 2. Due to the heterogeneous ligand substitution pattern, all d-type orbitals from the Ir atom exhibit sizable mixings with ligand orbitals. In particular, Ir orbitals in the $t_{2 g}$-like set combine with occupied p-type orbitals from the chloride ligand, the lone pairs of the phosphorous atoms and $\pi$-type orbitals from the Schiff base ligand. The two highest occupied MOs, HOMO and HOMO-1, of complex 2 are practically degenerate combinations of metal $\mathrm{d}_{x y}$ with chlorine $\mathrm{p}_{y}$ and metal $\mathrm{d}_{x z}$ with chlorine $\mathrm{p}_{z}$ AOs, respectively, with the HOMO-1 having an additional participation of $\pi$-type orbitals of the Schiff base ligand. The lowest unoccupied orbitals correspond mainly to $\pi^{*}$-type orbitals of the Schiff base ligand. The lowest unoccupied MO (LUMO) has a small contribution of the Ir atomic orbitals, while the LUMO+3 shows participation of orbitals from two phenyl rings on the phosphine ligands. Further details regarding the MOs of 2 can be found in the ESI. $\dagger$

The MO diagrams for complexes $\mathbf{1}$ and $\mathbf{3}$ are qualitatively very similar to that of 2 , except for subtle differences in the energies of the orbitals and the degree of mixing of fragment orbitals due to the differences in the Schiff bases. There is, though, an important difference between $\mathbf{4}$ and the other three complexes. Substitution of the Schiff base with an electrondonating diphenylamine group modifies dramatically its electronic structure. The HOMO is no longer an orbital centered on the iridium atom, but a pure $\pi$-type orbital of the donor amine unit (Fig. 2). The remaining frontier MOs of 4 are equivalent to those of 2.

\subsection{Photophysical properties in solution and thin films}

The lowest computed singlet and triplet states of complexes 1-3 correspond to excitations from the $\mathrm{d}_{x y}$ and $\mathrm{d}_{x z}$ type HOMOs to the Schiff base centered LUMO. Amplitude analysis of these excitations reveals that the corresponding excited states have important metal-to-ligand charge transfer (MLCT), ligand-toligand charge transfer (LLCT) from the chloride to the Schiff

Scheme 1 Synthesis of complexes 1-4. 

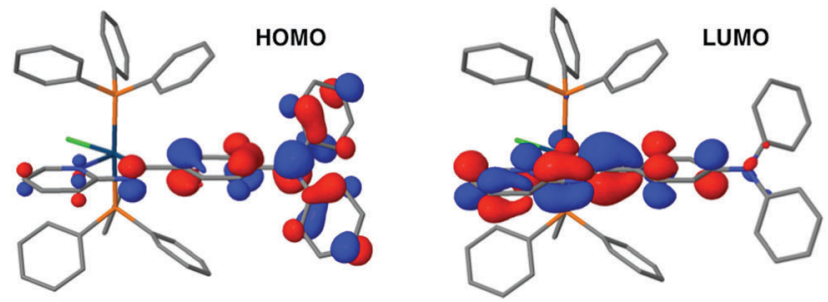

Fig. 2 HOMO and LUMO of the optimized ground state of 4 at the B3LYP/LANL2DZ,6-31G(d) level. Hydrogen atoms have been omitted for the sake of clarity.

base, and ligand-centered (LC) $\pi, \pi^{*}$ character in the case of the excited state involving the $\mathrm{d}_{x z}$ based occupied orbital. For simplicity, we will from now on refer to these excited states as MLLCTy and MLLCTz/LC, where $y$ and $z$ indicate the atomic $\mathrm{p}$ orbital of the chlorine atom involved in the occupied MO of the transition. The lowest excited singlet state for complexes 1-3 is MLLCTy, while the lowest triplet corresponds to MLLCTz/LC. In contrast, the lowest computed singlet and triplet states of complex 4 correspond to HOMO to LUMO transitions with ILCT character due to the donor nature of the diphenylamine substitution in the Schiff base. The computed vertical excitation energies to these states are gathered in Table 1.

The UV-VIS absorption spectra in DCM solution for 1-4 are shown in Fig. 3. The moderately intense band at 300-450 nm is assigned by our calculations to the ${ }^{1}$ MLLCT $z /$ LC state computed at $\sim 370 \mathrm{~nm}$ for all complexes. The absorption profiles of complexes 1-3 are very similar to each other, as predicted by the correspondence of their MO diagrams (Fig. 1). The absorption spectrum of complex 4 exhibits a rather intense band centered at $\sim 400 \mathrm{~nm}$ not present for the other three complexes, which is a signature of the ILCT transition in the Schiff base ligand. The vertical transition to ${ }^{1} \mathrm{ILCT}$ in 4 is computed at $416 \mathrm{~nm}$, in very good agreement with the experimental absorption maximum (404 nm). The simulated spectra of all complexes (ESI $\dagger$ ) reproduce reasonably well the band positions and relative intensities of the experimental absorption spectra.

We have explored the solvent polarity dependence of the absorption spectra of the studied complexes. While the absorption spectra of 1-3 show no dependence on solvent polarity, the absorption spectrum of complex 4 shows a weak dependence with the solvent dielectric constant due to the strong absorption of the ${ }^{1}$ ILCT state and its CT character (Fig. S13, ESI $\dagger$ ).

The normalized emission spectra of the synthesized complexes in DCM solution and in thin film are shown in Fig. 4.

Table 1 Vertical excitation energies (in $\mathrm{nm}$ ) and oscillator strengths $\geq 0.01$ (in parenthesis) for the lowest excited states of $1-4$. All values computed at the B3LYP/LANL2DZ,6-31G(d) level

\begin{tabular}{lllll}
\hline State & $\mathbf{1}$ & $\mathbf{2}$ & $\mathbf{3}$ & $\mathbf{4}$ \\
\hline${ }^{3}$ MLLCT $z /$ LC & 456 & 472 & 479 & 420 \\
${ }^{3}$ MLLCTy & 406 & 397 & 395 & 395 \\
${ }^{3}$ ILCT & - & - & - & 528 \\
${ }^{1}$ MLLCT $z /$ LC & $370(0.02)$ & $368(0.04)$ & $368(0.07)$ & $365(0.01)$ \\
${ }^{1}$ MLLCTy & 397 & 389 & 387 & 387 \\
${ }^{1}$ ILCT & - & - & - & $416(0.58)$
\end{tabular}

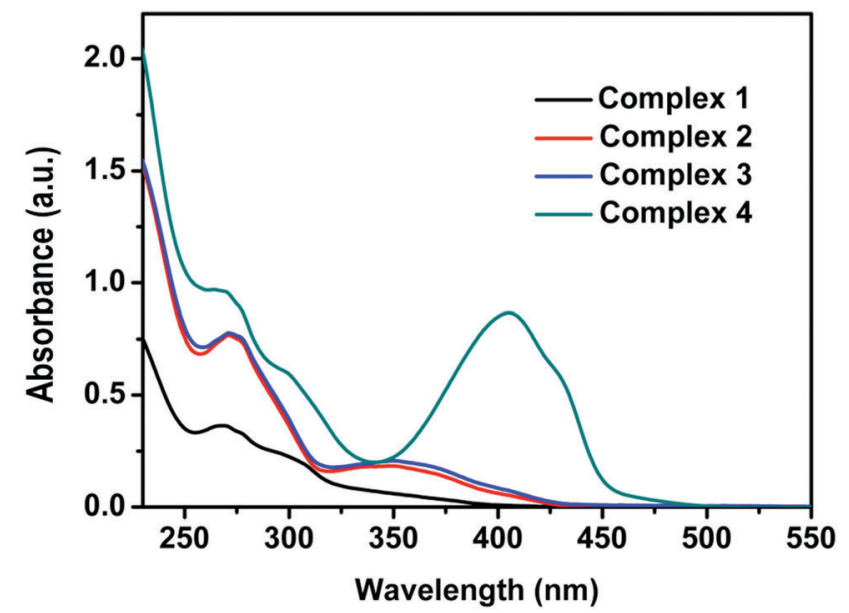

Fig. 3 UV-VIS absorption spectra (in arbitrary units) of 1-4 $\left(10^{-5} \mathrm{M}\right)$ recorded in degassed DCM at room temperature.

All complexes present structured emission profiles with a separation between the peaks on the order of $1300-1400 \mathrm{~cm}^{-1}$, which we assign to vibronic progressions. ${ }^{21,78,79}$ The position and relative intensity of the vibronic peaks in the thin film emission spectra are very close to their counterparts in solution. This matching is also reflected when comparing the emission colors in thin film with the emission colors in DCM solution shown in the chromaticity diagram (Fig. 5 and Table S4, ESI $\dagger$ ), for which the same green to yellow transition is observed.

Our calculations predict the ${ }^{3}$ MLLCTz/LC state as the one responsible for the phosphorescence emission of complexes 1-3. For all three complexes there is a nice agreement between the experimental emission spectra and the simulated vibrationally resolved phosphorescence profiles (Fig. 6, Fig. S32 and S33, ESI†).

For complexes 1-3, the main vibrational mode responsible for the structured emission is related to the stretching of the $\mathrm{C}=\mathrm{N}$ bond in the Schiff base, with a computed frequency of $\sim 1470-1450 \mathrm{~cm}^{-1}$ (Fig. S34, ESI $\dagger$ ). The distortion associated with this mode is in fact the main geometrical modification along the molecular relaxation on the $T_{1}$ state potential energy surface from the Franck-Condon region. Although this vibrational progression is the main contribution defining the overall shape of the emission spectra, there are other less intense normal modes also contributing to the emission profiles (Tables S5-S8, ESI $\dagger$ ).

The emission spectrum of $\mathbf{4}$ in solution exhibits two clearly distinct bands (Fig. 7): (i) a solvatochromic band at 400-525 nm and (ii) a structured emission band in the $525-700 \mathrm{~nm}$ region, very similar to the emission band in $\mathbf{1 - 3}$, that is practically independent of the solvent's polarity (Fig. S14, ESI $\dagger$ ). Due to this dual emissive behavior, the emission color of 4 may easily be tuned by varying the solvent's polarity. In particular, in low polarity solvents (benzene, 1,4-dioxane), the emission color of 4 is blue with an emission band maximum at $461 \mathrm{~nm}$, whereas in more polar solvents (ethyl acetate, $\mathrm{CHCl}_{3}$, DCM and THF) the emission gradually shifts to longer wavelengths. In strongly polar solvents (DMSO) complex 4 shows yellow emission (Fig. 7). 

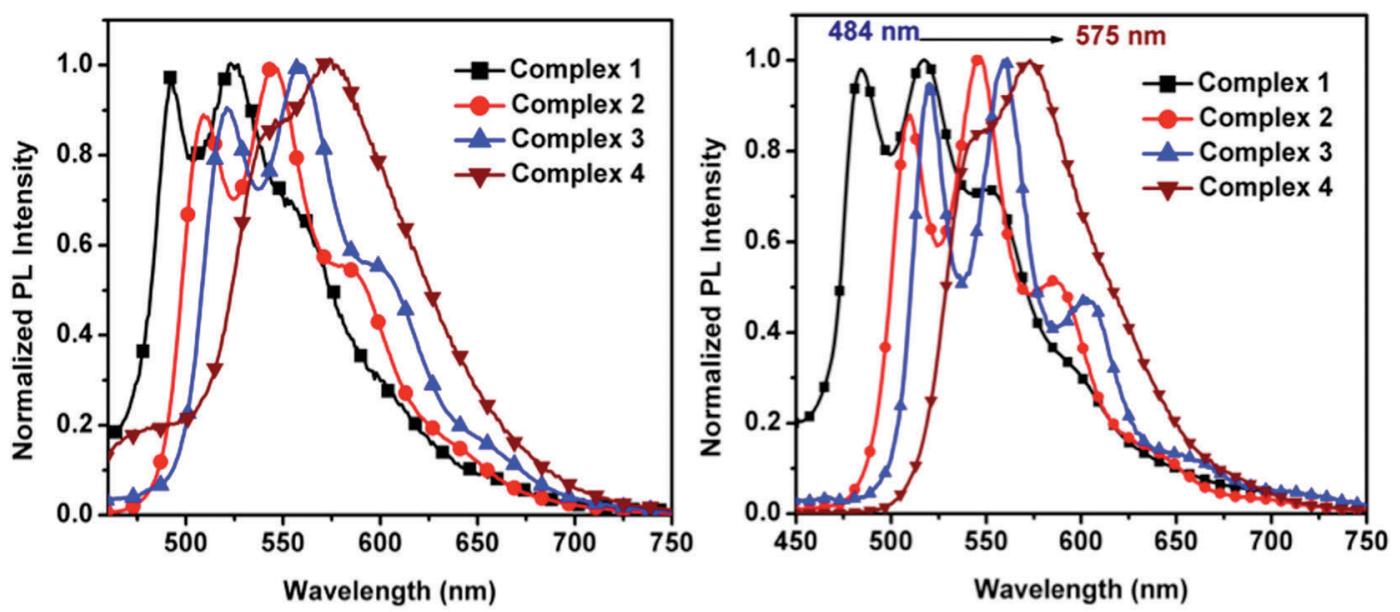

Fig. 4 Normalized emission spectra of 1-4 in degassed DCM at room temperature (left) and thin film (right).
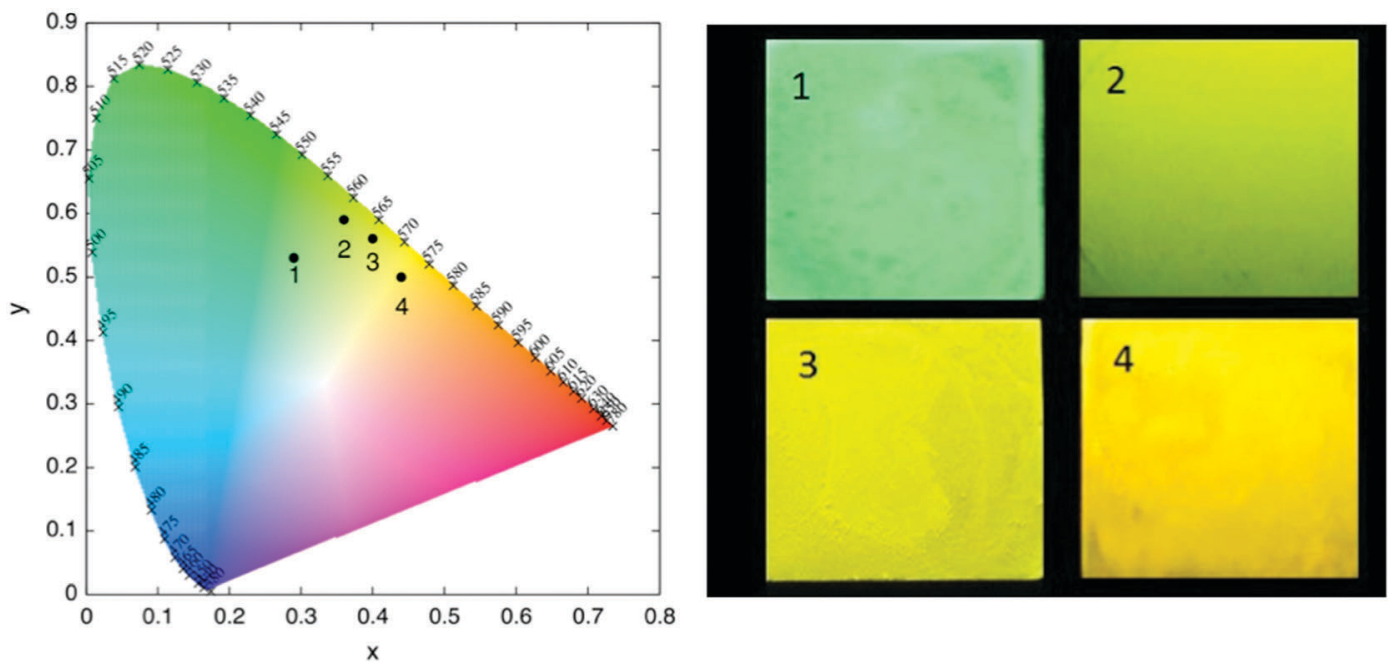

Fig. 5 Chromaticity diagram for the emission of 1-4 in DCM (left) and their respective thin film emission color under $365 \mathrm{~nm}$ UV lamp (right).

The similarities of the emission of 4 in the 525-700 $\mathrm{nm}$ region with the emission spectra of complexes 1-3 allow us to assign this band to the phosphorescence emission from the ${ }^{3} \mathrm{MLLCT} z / \mathrm{LC}$ state. On the other hand, our calculations indicate that the state responsible for the solvatochromic band below $500 \mathrm{~nm}$ corresponds to the singlet state with ILCT character. This assignment is also supported by time-resolved photoluminescence measurements by monitoring the emission maxima at $450 \mathrm{~nm}$ and $530 \mathrm{~nm}$ in different solvents (benzene, DCM, THF and DMSO). The lifetime data for the high-energy band is obtained within the 0.9-1.4 ns range, consistent with fluorescence emission (Fig. S15-S18 and Table S1, ESI $\dagger$ ). On the other hand, the lifetime measurements of the band at $530 \mathrm{~nm}$ are in the microsecond range (from 1.4 to $1.7 \mu \mathrm{s}$ ), consistent with phosphorescence emission. The ${ }^{1}$ ILCT state of $\mathbf{4}$ was optimized in strongly polar and non-polar solvents, i.e. DMSO and benzene, for which the experimental emission maxima were measured at 480 and $459 \mathrm{~nm}$, respectively. The calculated relative shift in the vertical emission energies of 4 in benzene and DMSO is $0.16 \mathrm{eV}$, in very good agreement with the shift observed in the experimental spectra $(0.12 \mathrm{eV})$. As the polarity of the solvent increases, the LUMO is more stabilized than the HOMO (Table S12, ESI $\dagger$ ), leading to the observed red-shift in the emission energy. Further calculations ruling out the possible formation of a twisted intramolecular charge transfer state (TICT) may be found in the ESI. $\dagger$

The observed red-shifted emission of the fluorescent ILCT band in highly polar solvents of $\mathbf{4}$ is also accompanied by a decrease in its PL intensity. This is clearly seen in Fig. 8, where the emission spectra of $\mathbf{4}$ recorded with different fractions of benzene $\left(f_{\mathrm{B}}\right)$ in THF are shown. The gradual addition of benzene to the THF solution results in a blue shifted emission with increasing PL intensity. The spectral data reveal that the intensity of the short wavelength band gradually increases with increasing benzene fractions.

Frozen samples of 4 in benzene and 1,4-dioxane at $-80{ }^{\circ} \mathrm{C}$ showed yellow emission under excitation at $365 \mathrm{~nm}$ (Fig. S19, ESI $\dagger$ ), while at room temperature a blue emission was observed. Since the yellow emission of $\mathbf{4}$ has been attributed to the 


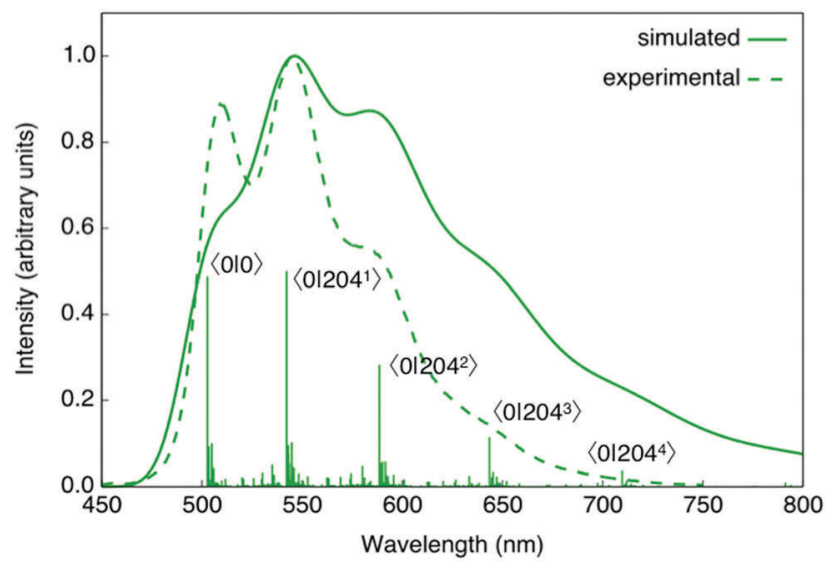

Fig. 6 Simulated (solid line) and experimental (dashed line) phosphorescence emission spectra of complex 2 . Vertical sticks indicate the relative strength of vibronic transitions contributing to the simulated spectrum. Both spectra have been normalized and the calculated spectrum has been blue shifted by $0.12 \mathrm{eV}$ to superimpose the most intense peaks. The 204 normal mode of vibration resulting in the vibrational structure corresponds to the $\mathrm{C}=\mathrm{N}$ stretching mode of the imine.

${ }^{3}$ MLLCTz/LC state, this suggests that molecular relaxation of the ${ }^{1}$ ILCT state from the Franck-Condon geometry is slowed down in the frozen samples, allowing the population of the ${ }^{3}$ MLLCTz/LC state via intersystem crossing.

Finally, the excitation and emission spectra recorded in different solvents are in agreement with a dual emission from two different states, i.e. ${ }^{1}$ ILCT and ${ }^{3}$ MLLCTz/LC (Fig. S20, ESI $\dagger$ ).

\subsection{Aggregation-induced enhanced emission}

All four synthesized complexes exhibit weak emission in common organic solvents such as DCM, THF, $\mathrm{MeOH}, \mathrm{CHCl}_{3}, \mathrm{ACN}$, or DMSO, but they are highly emissive in the solid state. Such strong solid-state emission encouraged us to study the AIEE of these complexes. Complexes 1-3 are highly soluble in THF but insoluble in water, thus we explored the effects of aggregation on their PL properties in THF-water with a wide range of mixing ratios. The formation of aggregates when water is present was confirmed using a particle size analyzer, indicating the formation of nano-aggregates with diameters in the range of 124-674 nm (Fig. S11, ESI $\dagger$ ). Solutions of 1-3 in pure THF emit weakly, while their emission gradually increases with the water fraction in THF-water mixtures. For mixtures with a high content of water $\left(f_{\mathrm{w}}=90 \%\right)$, the PL intensity of complexes $\mathbf{1}, 2$ and 3 is 45,18 , and 6 times stronger than that in pure THF solution (Fig. S21, ESI $\dagger$ ), respectively.

The AIEE property of $\mathbf{4}$ was also investigated in different solvents, namely THF, ACN and DMSO with gradual addition of water. The dilute solution of THF shows a faint green photoemission that intensifies and red shifts (from $535 \mathrm{~nm}$ to $578 \mathrm{~nm})$ at $f_{\mathrm{w}}=10 \%$. The addition of more water, $\left(f_{\mathrm{w}}=20 \%\right)$, leads again to a red shifted emission maximum (from $578 \mathrm{~nm}$ to $610 \mathrm{~nm}$ ) and to an increase of the emission intensity. We attribute this spectral change (red shifted emission) to the stabilization of the charge transfer state with increasing solvent polarity. ${ }^{80}$ A further increase of the water fraction up to $70 \%$ does not alter the emission maximum and its intensity. At $f_{\mathrm{w}}=80 \%$ however, a sudden blue shifted structured emission (516 $\mathrm{nm}$ and $557 \mathrm{~nm}$ ) appears along with a slight increase in the PL intensity. In contrast, the emission red shifts again (from $535 \mathrm{~nm}$ and $574 \mathrm{~nm}$ ) at $f_{\mathrm{w}}=90 \%$, but the structured profile remains and the PL intensity is 22 times higher than that in pure THF (Fig. 9). In this case, the observed emission enhancement at higher water content can also be safely attributed to aggregate formation (Fig. S11, ESI $\dagger$ ). In addition, we argue that closely spaced aggregates could be responsible for creating a less polar environment, resulting in a blue shifted emission. ${ }^{81,82}$

The emission behavior of $\mathbf{4}$ was also studied using mixtures with different ACN-water fractions (Fig. S22, ESI $\dagger$ ). The emission intensity of 4 doubles at $f_{\mathrm{w}}=30 \%$ in comparison to pure

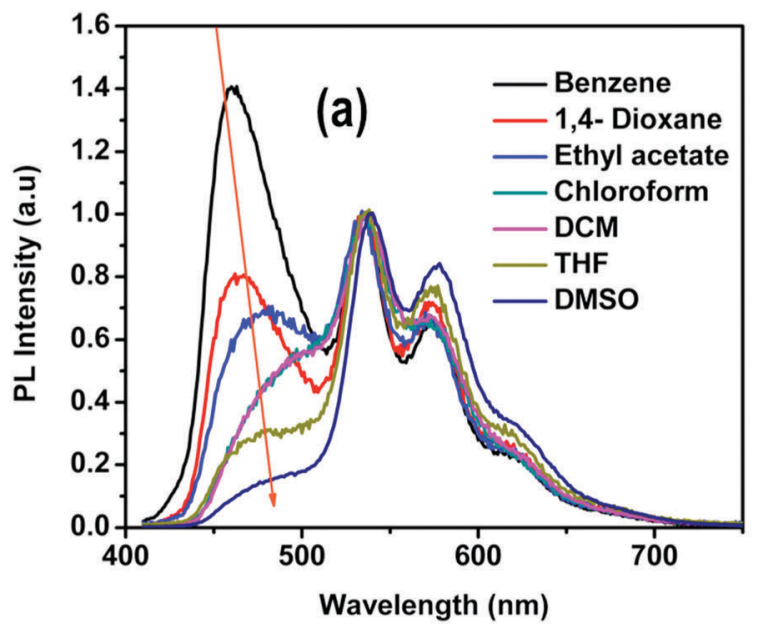

(b)

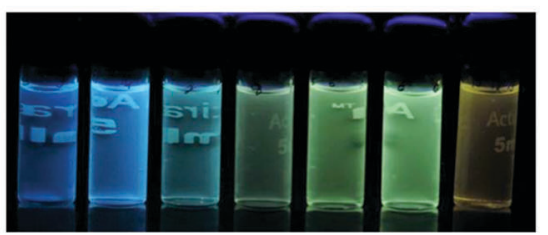

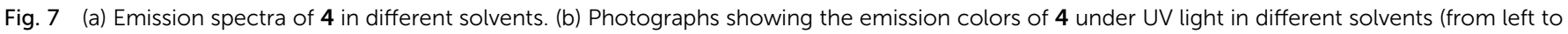

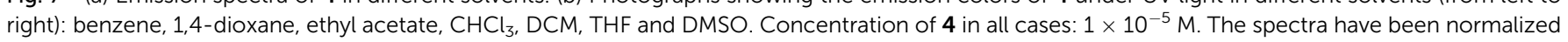
to the peak at $\sim 535 \mathrm{~nm}$. 

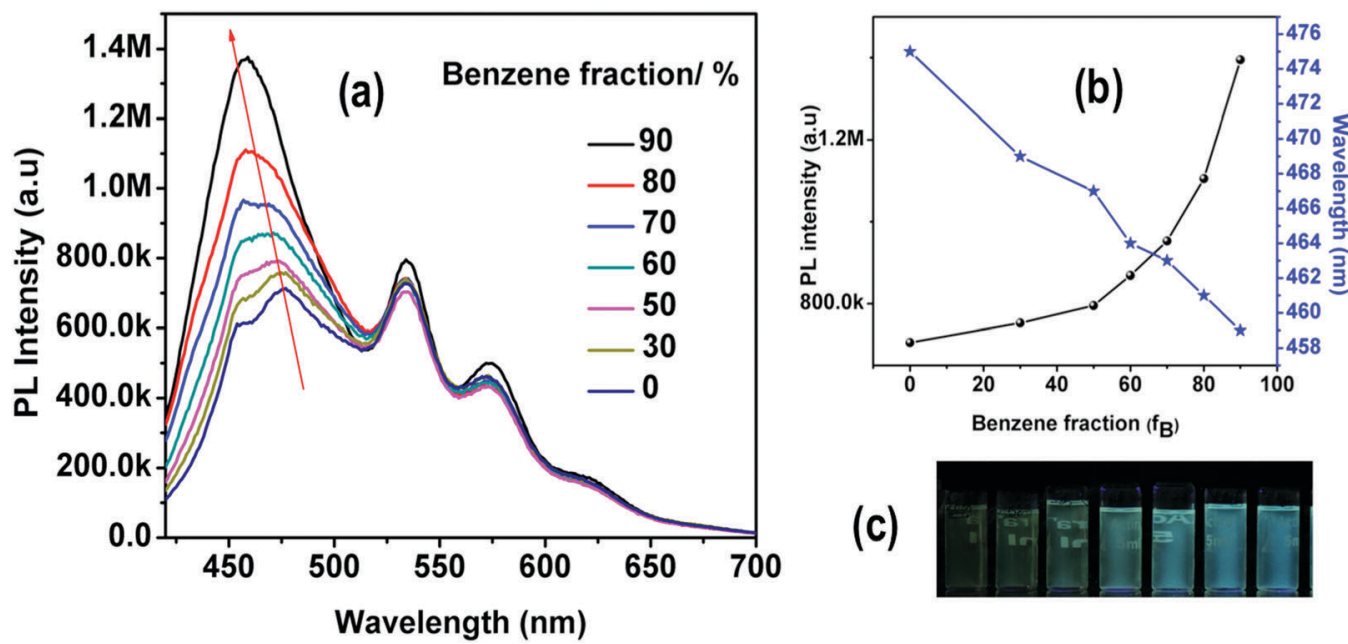

Fig. 8 (a) Emission spectra of 4 in THF with different benzene fractions (0-90\%). (b) Plots of maximum emission intensity and wavelength of 4 versus benzene fraction $\left(f_{B}\right)$ in the THF/Benzene mixture. Solution concentration: $1 \times 10^{-5} \mu \mathrm{M}$. (c) Photographs of 4 in THF/benzene mixtures with different fractions of benzene $\left(f_{\mathrm{B}}\right)$ taken under $365 \mathrm{~nm}$ UV illumination.
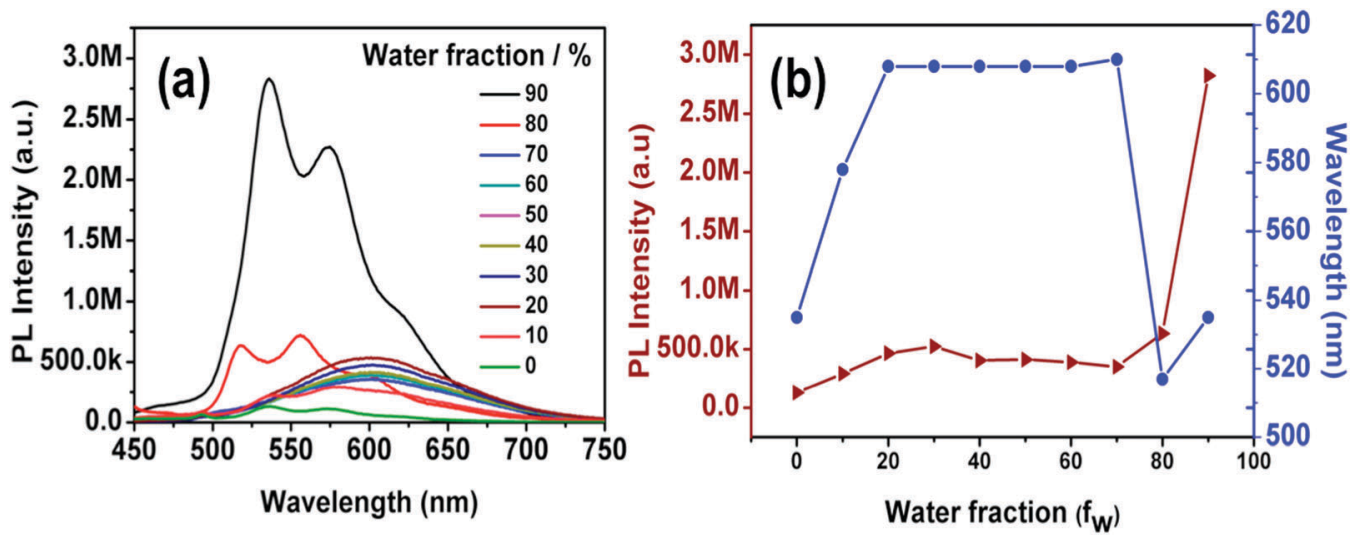

(c)

Fig. 9 (a) Emission spectra of 4 in THF/water mixtures (0-90\%). (b) Plot of maximum emission intensity and wavelength of 4 versus water fraction. Concentration of 4: $1 \times 10^{-5} \mathrm{M}$. (c) Photographs of $\mathbf{4}$ in THF/water mixtures taken under UV illumination.

ACN solution, while the emission maximum remains at $510 \mathrm{~nm}$. At $f_{\mathrm{w}}=50 \%$ the PL intensity increases by 5 times with respect to pure ACN solution and the emission maximum slightly red-shifts to $523 \mathrm{~nm}$. Further addition of water $\left(f_{\mathrm{w}}=70 \%\right)$ increases the PL intensity by 5 times in comparison to pure ACN solution, but now the emission band is no longer broad, displaying two distinct peaks at $517 \mathrm{~nm}$ and $552 \mathrm{~nm}$, respectively. The structured band remains at $f_{\mathrm{w}}=90 \%$ with a significant red shift to 538 and $580 \mathrm{~nm}$, however, the PL intensity weakens dramatically to only thrice that of the pure ACN solution.

The emission spectra of $\mathbf{4}$ in DMSO-water mixtures do not show any changes in the emission maximum, since there is already a highly polar environment in the pure organic solvent, but the PL intensity increases by 32 times as compared to the pure DMSO solution of the complex (Fig. 10).
The formation of nanoaggregates in the AIEE experiments of complex 4 was confirmed by the leveled-off tails ${ }^{81}$ in the visible region of the recorded UV-VIS spectra in different water fractions with DMSO, as well as with ACN (Fig. S23, ESI $\dagger$ ).

The AIEE of these complexes was further studied by measuring the absolute emission quantum yields (QY) for solid samples, and comparing these data with those obtained in DCM solution. The QY of these complexes in solution is $<0.1 \%$, while the absolute QY in the solid state is 3-9\% that is, about two orders of magnitude higher.

In order to explore the possibility of whether weak intermolecular interactions could be responsible for the restriction of intramolecular motions ${ }^{83,84}$ in the solid state and give rise to an enhancement of the PL intensity upon aggregation, the crystal packing of 2 was analyzed in detail considering that it 

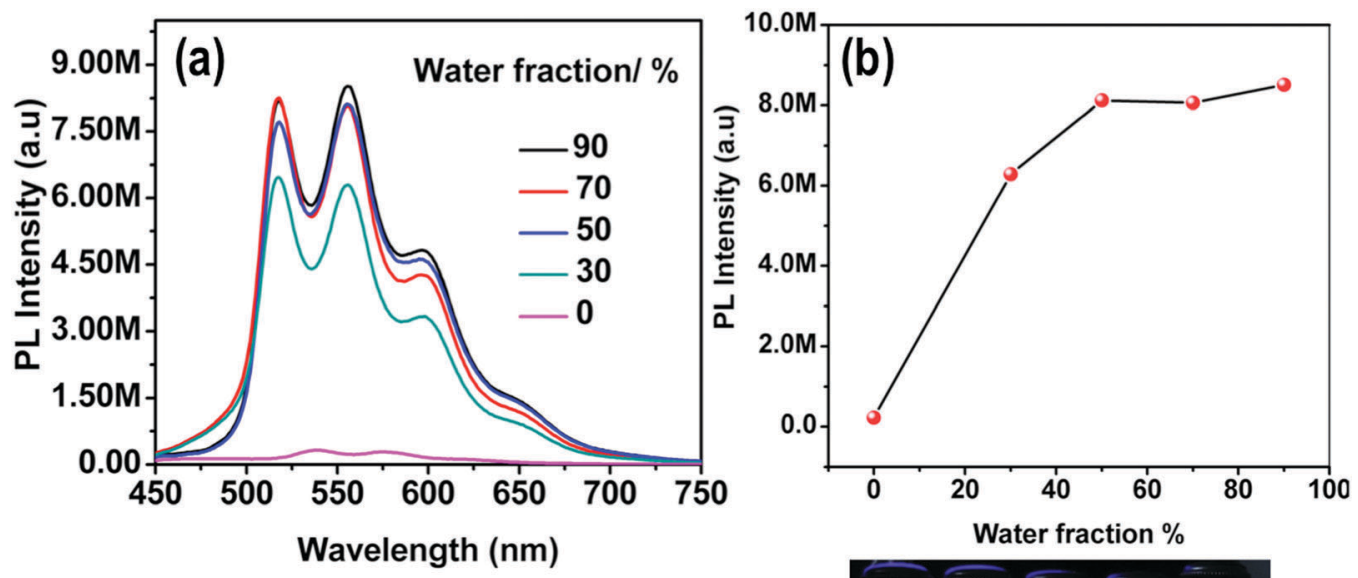

(c)

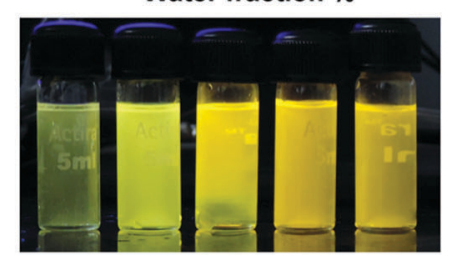

Fig. 10 (a) Emission spectra and (b) plot of maximum emission intensity of $\mathbf{4}$ in DMSO/water mixtures (0-90\%). Concentration of $\mathbf{4}$ : $1 \times 10^{-5} \mathrm{M}$. (c) Photographs of $\mathbf{4}$ in DMSO/water mixtures taken under UV illumination (excitation at $365 \mathrm{~nm}$ ).

might represent an acceptable structural model for the aggregates formed in the mixtures of water with organic solvents. The crystal structure of 2 has a unit cell with four equivalent Ir(III) complexes together with four cocrystallized ACN molecules exhibiting disorder in the position of their hydrogen atoms. Iridium complexes arrange in chains along the $b$-axis, with each chain being surrounded by six other chains in an approximate elongated hexagonal fashion as shown in Fig. 11. The molecules of the reference chain (highlighted in red) lie in the same $a c$-plane as the chains highlighted in grey. On the other hand, the chains shown in blue are displaced by half a unit cell along the $b$-axis with respect to the reference chain. Inspection of interatomic distances between molecules in the reference and grey chains indicates the absence of potentially important non-covalent interactions between them. The reference and blue chains, however, exhibit short interchain $\mathrm{C}-\mathrm{H} \cdots \mathrm{Cl}$ distances $(2.802 \AA)$ between the chloride ligand and a hydrogen atom from an adjacent $\mathrm{PPh}_{3}$ ligand, indicative of non-negligible interchain interactions that represent a possible source of restriction of molecular motions in the solid state (Fig. S37, ESI $\dagger$ ). Nevertheless, the most significant interactions are found along the chains themselves, where crystallized ACN solvent molecules alternate with iridium complexes, as shown in Fig. 12. An analysis of intermolecular distances hints to the presence of strong $\mathrm{C}-\mathrm{H} \cdots \pi$ interactions between each ACN molecule and two phenyl rings from $\mathrm{PPh}_{3}$ ligands of adjacent complexes. The computed interaction energy between one complex with the two neighboring ACN molecules was $9.1 \mathrm{kcal} \mathrm{mol}^{-1}$, confirming the presence of these $\mathrm{C}-\mathrm{H} \cdots \pi$ interactions.

Further calculations were carried out to investigate the origin of the observed disorder for the hydrogen atoms of the ACN molecules in the crystal structure. Calculation of the energy cost for a rotation of the methyl group of the solvent

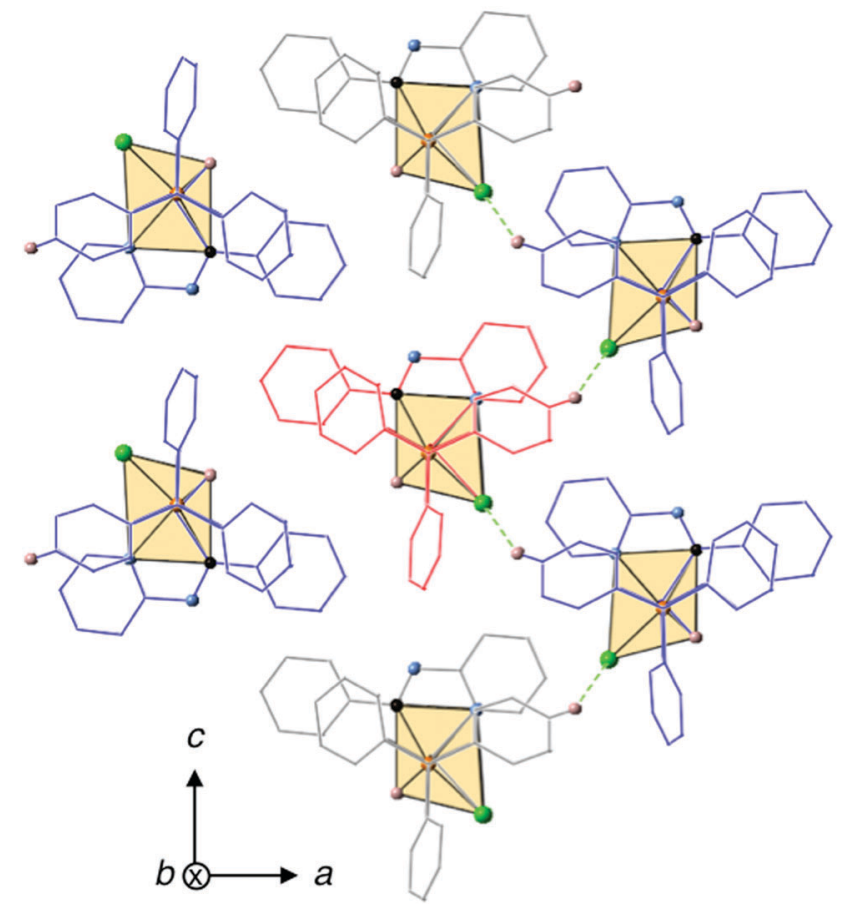

Fig. 11 Crystal packing of 2 with a reference chain highlighted in red. $\mathrm{C}-\mathrm{H} \cdots \mathrm{Cl}$ interactions $(2.802 \AA)$ between the chains are shown in green. Atom color code: nitrogen in blue, phosphorous in orange, chlorine in green, carbon in black and hydrogen in white. Hydrogen atoms not involved in intermolecular interactions are omitted for the sake of clarity.

molecule considering a fixed geometry was carried out in the presence of the two neighboring complexes (see Computational details). Two minima were obtained corresponding to the two hydrogen configurations found in the resolution of the crystal 


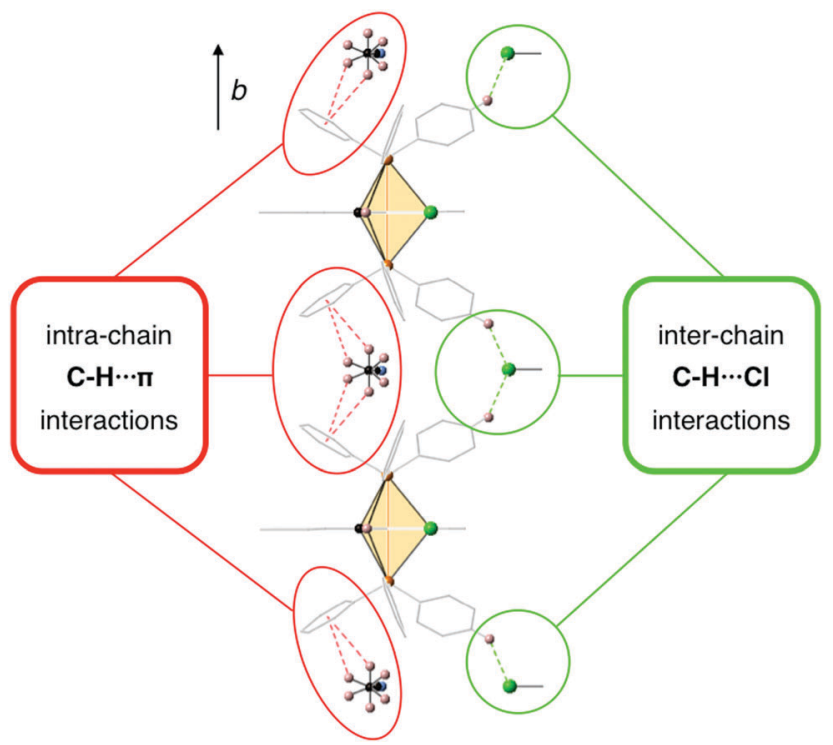

Fig. $12 \mathrm{C}-\mathrm{H} \cdots \pi$ interactions between $\mathrm{ACN}$ molecules and Ir(III) complexes along the crystal chains and inter-chain $\mathrm{C}-\mathrm{H} \cdots \mathrm{Cl}$ interactions with the chains highlighted in blue in Fig. 11. ACN molecules present dynamic disorder.

structure. The computed energy barrier $\left(0.3 \mathrm{kcal} \mathrm{mol}^{-1}\right)$ for the interconversion of the two conformations lies below the thermal energy $k T$ at the temperature of crystal determination (0.4 kcal mol $\left.\mathrm{m}^{-1}\right)$, suggesting that the origin of the observed disorder in the crystal structure is dynamic rather than static. These calculations show that in the crystal we should expect the methyl groups to rotate quite freely, establishing thus $\mathrm{C}-\mathrm{H} \cdots \pi$ interactions that restrict the motion of the $\mathrm{PPh}_{3}$ ligands and block non-radiative decay channels in the solid state with an increase of the emission intensity as a result. It has been recently shown that these types of interactions might play an important role in the solid state photophysics of iridium complexes. $^{20}$

\subsection{Reversible protonation-deprotonation}

We also performed photophysical studies of complexes 1-4 in the presence of TFA/ $\mathrm{Et}_{3} \mathrm{~N}$. Interestingly, addition of TFA triggers a considerable bathochromic shift in the thin film emission spectra of 1 and 4. The exposure of a thin film of 1 to TFA results in a broad emission band with a maximum at $539 \mathrm{~nm}$ responsible for a yellow color, which is highly reversible to its original green emission with maxima at $484 \mathrm{~nm}$ and $517 \mathrm{~nm}$ after exposure to $\mathrm{Et}_{3} \mathrm{~N}$ (Fig. 13). The yellow emitting thin film of 4 becomes red emissive with an emission maximum at $617 \mathrm{~nm}$ upon exposure to TFA. Likewise, subsequent $\mathrm{Et}_{3} \mathrm{~N}$ addition leads back to its original yellow emission. The thin films of complexes 2 and 3 also present reversible modification of the emission spectra under TFA/Et ${ }_{3} \mathrm{~N}$, although the emission color change is less pronounced (Fig. S24, ESI $\dagger$ ).

The reversibility of such protonation/deprotonation processes is confirmed by the ${ }^{1} \mathrm{H}$ NMR spectra of the protonated complexes (1-4) recorded in $\mathrm{CDCl}_{3}$ solution. ${ }^{1} \mathrm{H}$ NMR of complex 1 after exposure of the film to TFA shows a downfield signal at $\delta=9.01 \mathrm{ppm}$, not present in the absence of TFA. Similarly 2 , 3 and 4 display an even more downfield signal at $\delta=13.56$, 13.33, and $12.99 \mathrm{ppm}$, respectively. These ${ }^{1} \mathrm{H}$ NMR spectra indicate the transformation of these complexes into a protonated form, where the downfield ${ }^{1} \mathrm{H}$ signals may be attributed to the protonation of the nitrogen atom in the imine ligand unit (Fig. S12, ESI $\dagger$ ). Electronic structure calculations also suggest that the energetically most favorable protonation occurs on the iminic nitrogen for all complexes (Table S9, ESI $\dagger$ ). Computation of the protonated cationic form of complex 2 (labeled as $\mathbf{2 H}$ ) indicates that the most important geometrical difference with respect to the neutral complex is the larger torsion angle of the
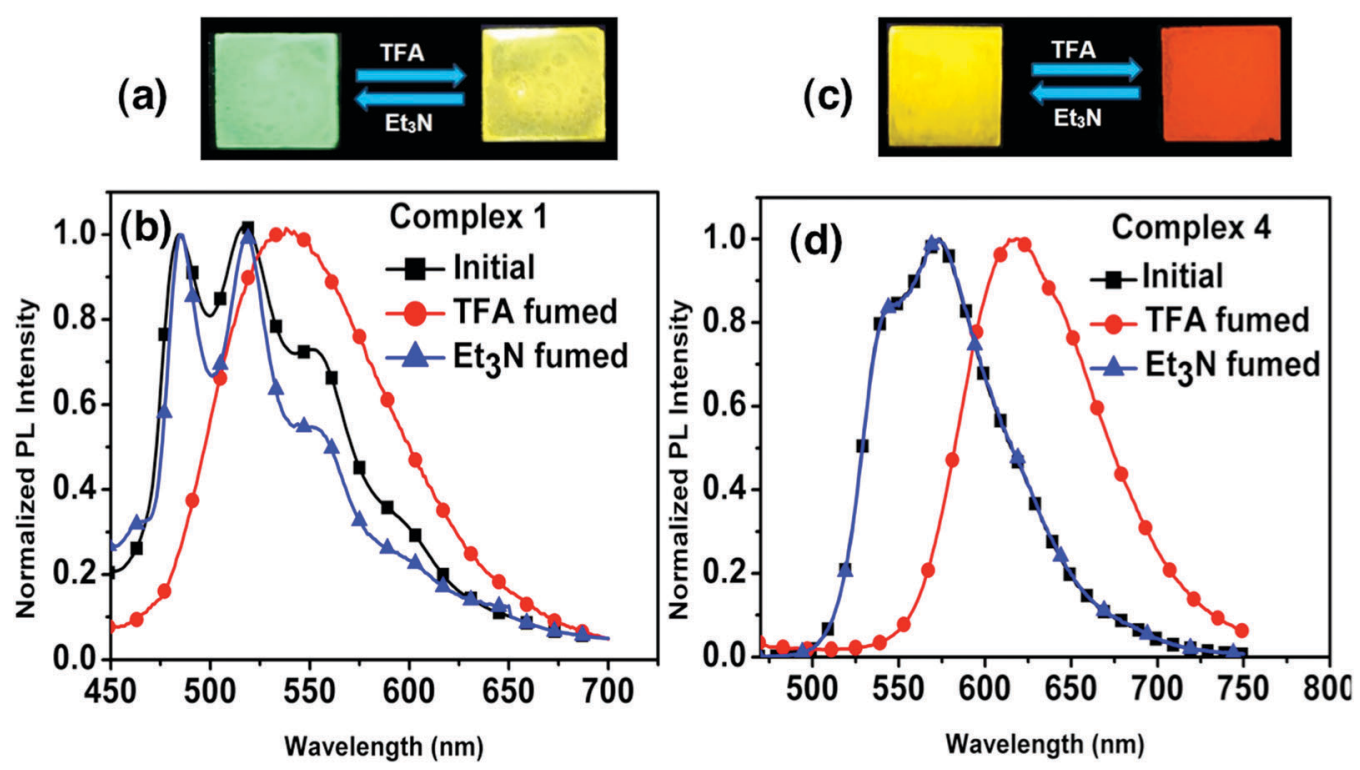

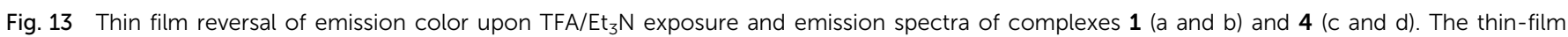
photographs and PL spectra were taken under an excitation wavelength of $365 \mathrm{~nm}$ and $400 \mathrm{~nm}$, respectively. 

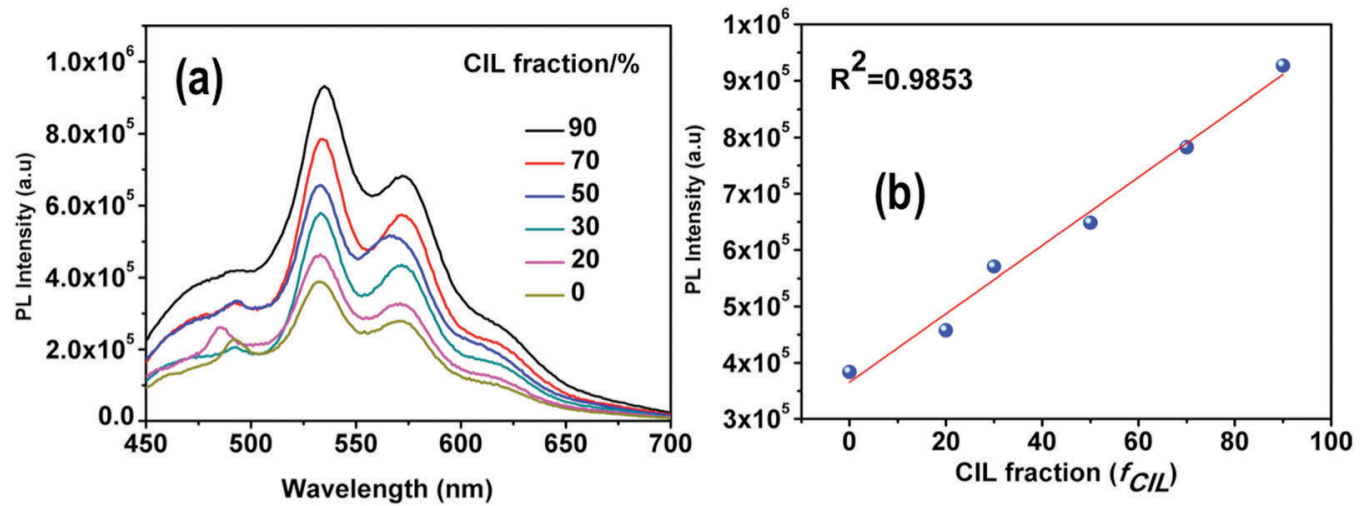

(c)

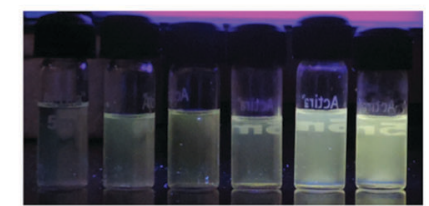

Fig. 14 (a) Emission spectra of 4 in DEA with different fractions of CIL (0-90\%). (b) Maximum emission intensity with respect to CIL. (c) Photographs of 4 in DEA/CIL mixtures taken under UV illumination.

phenyl ring of the Schiff base ligand due to steric hindrance between one of its hydrogen atoms and the protonating hydrogen (Fig. S38, ESI $\dagger$ ). In the unprotonated complex, the Schiff base ligand is completely planar, while in the $2 \mathbf{H}$ form the phenyl ring experiences a torsion of $22^{\circ}$ with respect to the complex's equatorial plane. Other structural differences of the coordination sphere of complex 2 upon protonation may be found in the ESI $\dagger$ (Table S10).

Protonation of the molecular species disrupts their electronic properties, resulting in changes in their photophysical behavior. Concretely, there is a reduction of the HOMO-LUMO gap upon protonation. Moreover, in the protonated form the electron density on the Schiff base ligand is strongly stabilized. As a result, the highest occupied orbitals with $\mathrm{d}_{x z}$ and $\mathrm{d}_{y z}$ participation do not show contributions from the conjugated systems of the bidentate ligand (Fig. S39, ESI $\dagger$ ), and the computed excitation energies to the ${ }^{3}$ MLLCT $y$ and ${ }^{3}$ MLLCT $z$ states are very close to each other (Table S11, ESI $\dagger$ ). These results point towards three factors responsible for the broad emission band with no vibrational structure observed upon exposure of the complexes to TFA: (i) the absence of LC character in the emitting triplet state, (ii) the loss of ligand planarity and (iii) the increase of molecular flexibility.

The dependence of the emission profiles for these complexes with $\mathrm{pH}$ suggests that these materials are potential candidates for $\mathrm{H}^{+}$detection. Additional spectra of 1-4 in solution with the presence of TFA may be found in the ESI $\dagger$ (Fig. S25 and S26).

\section{$3.5 \mathrm{CO}_{2}$ detection}

The solubility of $\mathbf{4}$ was screened with different amines, e.g. pyridine, 1,8-diazabi-cyclo-[5,4,0]-undec-7-ene (DBU), piperidine and diethyl amine (DEA). Complex 4 was found to be completely soluble in DEA. The reaction between DEA and $\mathrm{CO}_{2}$ yields a viscous carbamate ionic liquid (CIL). In this case, the CIL was synthesized by a simple reaction condition where the DEA solution was purged by a large excess of $\mathrm{CO}_{2}$ gas for 10 minutes.
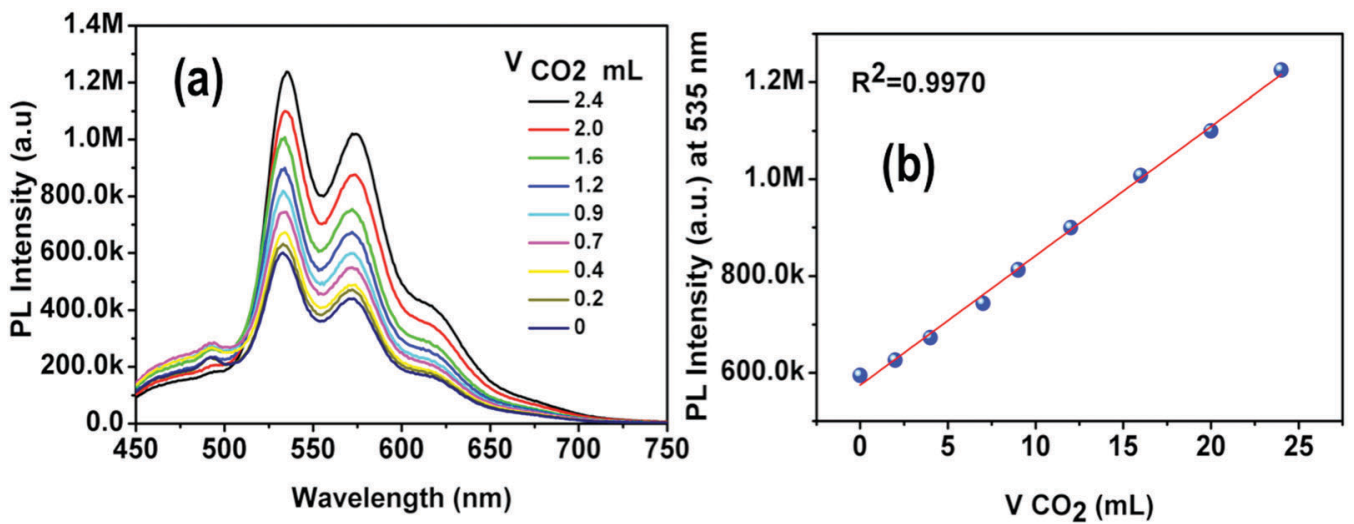

Fig. 15 (a) PL spectra of $\mathbf{4}$ in DPA with different volumes of $\mathrm{CO}_{2}$ displaying a gradual enhancement of the PL intensity. (b) The PL intensity increased in a linear fashion $\left(R^{2}=0.9970\right)$ with gradual addition of $\mathrm{CO}_{2}$. 
The synthesized CIL was characterized by ${ }^{1} \mathrm{H}$ NMR and ${ }^{13} \mathrm{C}$ NMR spectroscopy and the results matched satisfactorily with earlier reports $^{54}$ (Fig. S6, ESI $\dagger$ ).

The weak emission of complex 4 in DEA solution becomes gradually more intense after purging of $\mathrm{CO}_{2}$ bubbles. In fact, there is a linear relationship between the amount of CIL gradually added into the solution $\left(f_{\mathrm{CIL}}\right)$ and the emission intensity of the sample. At $f_{\mathrm{CIL}}=90 \%$, the PL intensity is 2.4 times stronger as compared to the intensity of the DEA solution (Fig. 14). This emission enhancement may be attributed to the increase in the viscosity of the medium that leads to a restriction of the motion of the phenyl rings in the $\mathrm{PPh}_{3}$ ligands possibly responsible for non-radiative decay. The increase of the PL intensity of complex 4 with the viscosity of the environment has been confirmed by comparing the emission spectra in PEG-THF mixtures (Fig. S27, ESI $\dagger$ ). To further analyze the response of 4 in DEA solutions to $\mathrm{CO}_{2}$, additional experiments were carried out in which different fractions of $\mathrm{CO}_{2}$ were purged through a solution of $\mathbf{4}$ in DEA at a fixed rate and time. The emission of 4 was enhanced by gradual addition of $\mathrm{CO}_{2}$ in the system and resulted in a linear plot for the whole concentration range. These results indicate the potential use of DEA diluted complex 4 as a quantitative detector of $\mathrm{CO}_{2}$ (Fig. 15). Although the addition of $\mathrm{CO}_{2}$ facilitates the removal of $\mathrm{O}_{2}$ from the sample which might result in a larger emission intensity, it cannot account for the large PL intensity increase observed.

\section{Conclusions}

In this study we have demonstrated a convenient route for the synthesis of a new series of 'Aggregation-Induced Enhanced Emission' (AIEE) active Ir(III) Schiff base complexes with facile color tuning. The calculations indicate that the triplet state responsible for the vibrationally structured phosphorescence band of the synthesized complexes is of mixed MLLCT and LC character of the Schiff base. The presence of a donor-acceptor unit in $\mathbf{4}$ is responsible for the additional fluorescence emission observed and its positive solvatochromism (increase in emission wavelength with increase in solvent polarity). The excited state responsible for this fluorescence has been characterized by our calculations as an ILCT state of the Schiff base ligand. Such dual emission present in $\mathbf{4}$ accounts for an outstanding color tuning from blue to yellow. In addition, 4 was found to be a probe molecule whose ILCT emission gradually increases with an increasing content of non-polar solvent (benzene) in polar media (THF). The crystal packing of 2 was analyzed revealing significant intra-chain $\mathrm{C}-\mathrm{H} \cdots \pi$ interactions $\left(\sim 9 \mathrm{kcal} \mathrm{mol}^{-1}\right)$ and interchain $\mathrm{C}-\mathrm{H} \cdots \mathrm{Cl}$ interactions, which could be responsible for the hindering of internal motions of the $\mathrm{PPh}_{3}$ ligands, blocking the non-radiative decay channels and hence enhancing the emission in the solid state. Thin films of the synthesized complexes were successfully employed for reversible detection of acidic and basic vapors. Calculations and ${ }^{1} \mathrm{H}$ NMR spectra hint at protonation of the iminic nitrogen as being responsible for the changes observed in the emission spectra of the thin films upon TFA exposure. An easy method for $\mathrm{CO}_{2}$ detection was also developed with $\mathbf{4}$ using a phosphorescence technique controlled by the viscosity of the medium. All the properties studied in this work point towards the potential application of the newly synthesized complexes as multi-responsive luminescent materials.

\section{Acknowledgements}

This work was supported by the Basque Govt. (project IT588-13) and the Spanish Govt. (MINECO/FEDER projects CTQ201564579-C3-3-P and CTQ2016-80955). We are thankful to DST, Govt. of India, under a project (no. SB/S1/IC-13/2014) and CSIR, Govt. of India, (no. 01/2551/12/EMR-II) for financial assistance. The UGC-SAP and DST-FIST, Govt. of India, are acknowledged for the instrumental support to the Department of Chemistry, BITS Pilani. We thank Dr Neetu Singh, advanced instrumentation research facility, JNU, New Delhi (India), for providing technical help on time resolved fluorescence spectroscopy. IISER Mohali is acknowledged for providing the X-ray diffraction and NMR facilities. D.C. thanks IKERBASQUE, Basque Foundation for Science for financial support. C.C. is indebted to the Spanish "Ministerio de Economía y Competitividad" for a predoctoral FPI grant.

\section{References}

1 C. Adachi, M. A. Baldo, M. E. Thompson and S. R. Forrest, Nearly $100 \%$ internal phosphorescence efficiency in an organic light-emitting device, J. Appl. Phys., 2001, 90, 5048.

2 M. A. Baldo, M. E. Thompson and S. R. Forrest, Highefficiency fluorescent organic light-emitting devices using a phosphorescent sensitizer, Nature, 2000, 403, 750.

3 H. Yersin, Highly Efficient OLEDs with Phosphorescent Materials, Wiley-VCH, Weinheim, 2008.

4 D. A. Nagib, M. E. Scott and D. W. C. MacMillan, Enantioselective $\alpha$-Trifluoromethylation of Aldehydes via Photoredox Organocatalysis, J. Am. Chem. Soc., 2009, 131, 10875.

5 A. Kobayashi and M. Kato, Vapochromic Platinum(II) Complexes: Crystal Engineering toward Intelligent Sensing Devices, Eur. J. Inorg. Chem., 2014, 4469.

6 O. S. Wenger, Vapochromism in Organometallic and Coordination Complexes: Chemical Sensors for Volatile Organic Compounds, Chem. Rev., 2013, 113, 3686.

7 X. Zhang, B. Li, Z.-H. Chen and Z.-N. Chen, Luminescence vapochromism in solid materials based on metal complexes for detection of volatile organic compounds (VOCs), J. Mater. Chem., 2012, 22, 11427.

8 K. K.-W. Lo, C.-K. Chung, T. K.-M. Lee, L.-H. Lui, K. H.-K. Tsang and $\mathrm{N}$. Zhu, New Luminescent Cyclometalated Iridium(III) Diimine Complexes as Biological Labeling Reagents, Inorg. Chem., 2003, 42, 6886.

9 K. K.-W. Lo, P.-K. Lee and J. S.-Y. Lau, Synthesis, Characterization, and Properties of Luminescent Organoiridium(III) Polypyridine Complexes Appended with an Alkyl Chain and 
Their Interactions with Lipid Bilayers, Surfactants, and Living Cells, Organometallics, 2008, 27, 2998.

10 K. K.-W. Lo, M.-W. Louie and K. Y. Zhang, Design of luminescent iridium(III) and rhenium(I) polypyridine complexes as in vitro and in vivo ion, molecular and biological probes, Coord. Chem. Rev., 2010, 254, 2603.

11 P. Alam, G. Kaur, C. Climent, S. Pasha, D. Casanova, P. Alemany, A. Roy Choudhury and I. R. Laskar, New aggregation induced emission (AIE) active cyclometalated iridium(III) based phosphorescent sensors: high sensitivity for mercury(II) ions, Dalton Trans., 2014, 43, 16431.

12 P. Alam, G. Kaur, V. Kachwal, A. Gupta, A. Roy Choudhury and I. R. Laskar, Highly sensitive explosive sensing by aggregation induced phosphorescence active cyclometalated iridium(III) complexes, J. Mater. Chem. C, 2015, 3, 5450.

13 P. Alam, G. Kaur, A. Sarmah, R. K. Roy, A. R. Choudhury and I. R. Laskar, Highly Selective Detection of $\mathrm{H}^{+}$and $\mathrm{OH}^{-}$with a Single-Emissive Iridium(III) Complex: A Mild Approach to Conversion of Non-AIEE to AIEE Complex, Organometallics, 2015, 34, 4480 .

14 J. Chen, B. Xu, X. Ouyang, B. Z. Tang and Y. Cao, Aggregation-Induced Emission of cis, cis-1,2,3,4-Tetraphenylbutadiene from Restricted Intramolecular Rotation, J. Phys. Chem. A, 2004, 108, 7522.

15 Y. Hong, J. W. Y. Lam and B. Z. Tang, Aggregation-induced emission: phenomenon, mechanism and applications, Chem. Commun., 2009, 4332.

16 J. Mei, Y. Hong, J. W. Y. Lam, A. Qin, Y. Tang and B. Z. Tang, Aggregation-Induced Emission: The Whole Is More Brilliant than the Parts, Adv. Mater., 2014, 26, 5429.

17 J. Mei, N. L. C. Leung, R. T. K. Kwok, J. W. Y. Lam and B. Z. Tang, Aggregation-Induced Emission: Together We Shine, United We Soar!, Chem. Rev., 2015, 115, 11718.

18 V. Sathish, A. Ramdass, P. Thanasekaran, K.-L. Lu and S. Rajagopal, Aggregation-induced phosphorescence enhancement (AIPE) based on transition metal complexes-An overview, J. Photochem. Photobiol., C, 2015, 23, 25.

19 P. Alam, S. Dash, C. Climent, G. Kaur, A. R. Choudhury, D. Casanova, P. Alemany, R. Chowdhury and I. R. Laskar, 'Aggregation induced emission' active iridium(III) complexes with applications in mitochondrial staining, $R S C$ Adv., 2017, 7, 5642.

20 P. Alam, C. Climent, G. Kaur, D. Casanova, A. Roy Choudhury, A. Gupta, P. Alemany and I. R. Laskar, Exploring the Origin of Aggregation Induced Emission Activity and Crystallization Induced Emission in Organometallic Iridium(III) Cationic Complexes: Influence of Counterions, Cryst. Growth Des., 2016, 16, 5738.

21 P. Alam, I. R. Laskar, C. Climent, D. Casanova, P. Alemany, M. Karanam, A. R. Choudhury and J. R. Butcher, Microwaveassisted facile and expeditive syntheses of phosphorescent cyclometallated iridium(III) complexes, Polyhedron, 2013, 53, 286.

22 Y. Jiang, G. Li, W. Che, Y. Liu, B. Xu, G. Shan, D. Zhu, Z. Su and M. R. Bryce, A neutral dinuclear Ir(III) complex for anticounterfeiting and data encryption, Chem. Commun., 2017, 53, 3022 .
23 G. Li, W. Guan, S. Du, D. Zhu, G. Shan, X. Zhu, L. Yan, Z. Su, M. R. Bryce and A. P. Monkman, Anion-specific aggregation induced phosphorescence emission (AIPE) in an ionic iridium complex in aqueous media, Chem. Commun., 2015, 51, 16924.

24 G. Li, X. Ren, G. Shan, W. Che, D. Zhu, L. Yan, Z. Su and M. R. Bryce, New AIE-active dinuclear Ir(III) complexes with reversible piezochromic phosphorescence behaviour, Chem. Commun., 2015, 51, 13036.

25 G. Li, Y. Wu, G. Shan, W. Che, D. Zhu, B. Song, L. Yan, Z. Su and M. R. Bryce, New ionic dinuclear Ir(III) Schiff base complexes with aggregation-induced phosphorescent emission (AIPE), Chem. Commun., 2014, 50, 6977.

26 G.-G. Shan, H.-B. Li, H.-Z. Sun, D.-X. Zhu, H.-T. Cao and Z.-M. Su, Controllable synthesis of iridium(III)-based aggregation-induced emission and/or piezochromic luminescence phosphors by simply adjusting the substitution on ancillary ligands, J. Mater. Chem. C, 2013, 1, 1440.

27 Y. Wu, H.-Z. Sun, H.-T. Cao, H.-B. Li, G.-G. Shan, Y.-A. Duan, Y. Geng, Z.-M. Su and Y. Liao, Stepwise modulation of the electron-donating strength of ancillary ligands: understanding the AIE mechanism of cationic iridium(III) complexes, Chem. Commun., 2014, 50, 10986.

28 K.-Y. Zhao, G.-G. Shan, Q. Fu and Z.-M. Su, Tuning Emission of AIE-Active Organometallic Ir(III) Complexes by Simple Modulation of Strength of Donor/Acceptor on Ancillary Ligands, Organometallics, 2016, 35, 3996.

29 A. J. Howarth, R. Patia, D. L. Davies, F. Lelj, M. O. Wolf and K. Singh, Elucidating the Origin of Enhanced Phosphorescence Emission in the Solid State (EPESS) in Cyclometallated Iridium Complexes, Eur. J. Inorg. Chem., 2014, 3657.

30 K. Huang, H. Wu, M. Shi, F. Li, T. Yi and C. Huang, Reply to comment on aggregation-induced phosphorescent emission (AIPE) of iridium(III) complexes: origin of the enhanced phosphorescence, Chem. Commun., 2009, 1243.

31 Y. You, H. S. Huh, K. S. Kim, S. W. Lee, D. Kim and S. Y. Park, Comment on aggregation-induced phosphorescent emission (AIPE) of iridium(III) complexes: origin of the enhanced phosphorescence, Chem. Commun., 2008, 3998.

32 Q. Zhao, L. Li, F. Li, M. Yu, Z. Liu, T. Yi and C. Huang, Aggregation-induced phosphorescent emission (AIPE) of iridium(III) complexes, Chem. Commun., 2008, 685.

33 B. M. J. S. Paulose, D. K. Rayabarapu, J. P. Duan and C. H. Cheng, First Examples of Alkenyl Pyridines as Organic Ligands for Phosphorescent Iridium Complexes, Adv. Mater., 2004, 16, 2003.

34 D. K. Rayabarapu, B. M. J. S. Paulose, J. P. Duan and C. H. Cheng, New Iridium Complexes with Cyclometalated Alkenylquinoline Ligands as Highly Efficient Saturated RedLight Emitters for Organic Light-Emitting Diodes, Adv. Mater., 2005, 17, 349.

35 C. S. Chin, M.-S. Eum, S. y. Kim, C. Kim and S. K. Kang, New Type of Photoluminescent Iridium Complex: Novel Synthetic Route for Cationic trans-Bis(2-phenylpyridinato)iridium(III) Complex, Eur. J. Inorg. Chem., 2006, 4979.

36 M.-S. Eum, C. S. Chin, S. y. Kim, C. Kim, S. K. Kang, N. H. Hur, J. H. Seo, G. Y. Kim and Y. K. Kim, Ligand 
Effects on Luminescence of New Type Blue Light-Emitting Mono(2-phenylpyridinato)iridium(III) Complexes, Inorg. Chem., 2008, 47, 6289.

37 P. Alam, P. Das, C. Climent, M. Karanam, D. Casanova, A. R. Choudhury, P. Alemany, N. R. Jana and I. R. Laskar, Facile tuning of the aggregation-induced emission wavelength in a common framework of a cyclometalated iridium(III) complex: micellar encapsulated probe in cellular imaging, J. Mater. Chem. C, 2014, 2, 5615.

38 X. Yang, X. Xu, J. Zhao, J.-s. Dang, Z. Huang, X. Yan, G. Zhou and D. Wang, Phosphorescent Platinum(II) Complexes Bearing 2-Vinylpyridine-type Ligands: Synthesis, Electrochemical and Photophysical Properties, and Tuning of Electrophosphorescent Behavior by Main-Group Moieties, Inorg. Chem., 2014, 53, 12986.

39 K. K.-W. Lo, Luminescent Rhenium(I) and Iridium(III) Polypyridine Complexes as Biological Probes, Imaging Reagents, and Photocytotoxic Agents, Acc. Chem. Res., 2015, 48, 2985.

40 A. J. Howarth, D. L. Davies, F. Lelj, M. O. Wolf and B. O. Patrick, Tuning the Emission Lifetime in Biscyclometalated Iridium(III) Complexes Bearing Iminopyrene Ligands, Inorg. Chem., 2014, 53, 11882.

41 S. Kumar, Y. Hisamatsu, Y. Tamaki, O. Ishitani and S. Aoki, Design and Synthesis of Heteroleptic Cyclometalated Iridium(III) Complexes Containing Quinoline-Type Ligands that Exhibit Dual Phosphorescence, Inorg. Chem., 2016, 55, 3829.

42 S. Ladouceur, L. Donato, M. Romain, B. P. Mudraboyina, M. B. Johansen, J. A. Wisner and E. Zysman-Colman, A rare case of dual emission in a neutral heteroleptic iridium(III) complex, Dalton Trans., 2013, 42, 8838.

43 K. K.-W. Lo, K. Y. Zhang, S.-K. Leung and M.-C. Tang, Exploitation of the Dual-emissive Properties of Cyclometalated Iridium(III)-Polypyridine Complexes in the Development of Luminescent Biological Probes, Angew. Chem., Int. Ed., 2008, 47, 2213.

44 Y.-S. Yeh, Y.-M. Cheng, P.-T. Chou, G.-H. Lee, C.-H. Yang, Y. Chi, C.-F. Shu and C.-H. Wang, A New Family of Homoleptic Ir(III) Complexes: Tris-Pyridyl Azolate Derivatives with Dual Phosphorescence, ChemPhysChem, 2006, 7, 2294.

45 Y. You, S. Cho and W. Nam, Cyclometalated Iridium(III) Complexes for Phosphorescence Sensing of Biological Metal Ions, Inorg. Chem., 2014, 53, 1804.

46 Y. You, Y. Han, Y.-M. Lee, S. Y. Park, W. Nam and S. J. Lippard, Phosphorescent Sensor for Robust Quantification of Copper(II) Ion, J. Am. Chem. Soc., 2011, 133, 11488.

47 K. Y. Zhang, H.-W. Liu, M.-C. Tang, A. W.-T. Choi, N. Zhu, X.-G. Wei, K.-C. Lau and K. K.-W. Lo, Dual-Emissive Cyclometalated Iridium(III) Polypyridine Complexes as Ratiometric Biological Probes and Organelle-Selective Bioimaging Reagents, Inorg. Chem., 2015, 54, 6582.

48 T. Guo, W. Zhong, J. Zou, L. Ying, W. Yang and J. Peng, Efficient binary white light-emitting polymers grafted with iridium complexes as side groups, RSC Adv., 2015, 5, 89888.

49 H. Shi, H. Sun, H. Yang, S. Liu, G. Jenkins, W. Feng, F. Li, Q. Zhao, B. Liu and W. Huang, Cationic Polyfluorenes with
Phosphorescent Iridium(III) Complexes for Time-Resolved Luminescent Biosensing and Fluorescence Lifetime Imaging, Adv. Funct. Mater., 2013, 23, 3268.

50 Z. Song, R. Liu, Y. Li, H. Shi, J. Hu, X. Cai and H. Zhu, AIEactive $\operatorname{Ir}(\mathrm{III})$ complexes with tunable emissions, mechanoluminescence and their application for data security protection, J. Mater. Chem. C, 2016, 4, 2553.

51 T. Yoshihara, S. Murayama and S. Tobita, Ratiometric Molecular Probes Based on Dual Emission of a Blue Fluorescent Coumarin and a Red Phosphorescent Cationic Iridium(III) Complex for Intracellular Oxygen Sensing, Sensors, 2015, 15, 13503.

52 Z. Guo, N. R. Song, J. H. Moon, M. Kim, E. J. Jun, J. Choi, J. Y. Lee, C. W. Bielawski, J. L. Sessler and J. Yoon, A Benzobisimidazolium-Based Fluorescent and Colorimetric Chemosensor for $\mathrm{CO}_{2}$, J. Am. Chem. Soc., 2012, 134, 17846.

53 M. Ishida, P. Kim, J. Choi, J. Yoon, D. Kim and J. L. Sessler, Benzimidazole-embedded N-fused aza-indacenes: synthesis and deprotonation-assisted optical detection of carbon dioxide, Chem. Commun., 2013, 49, 6950.

54 Y. Liu, Y. Tang, N. N. Barashkov, I. S. Irgibaeva, J. W. Y. Lam, R. Hu, D. Birimzhanova, Y. Yu and B. Z. Tang, Fluorescent Chemosensor for Detection and Quantitation of Carbon Dioxide Gas, J. Am. Chem. Soc., 2010, 132, 13951.

55 W. Lu, P. Xiao, J. Gu, J. Zhang, Y. Huang, Q. Huang and T. Chen, Aggregation-induced emission of tetraphenylethylene-modified polyethyleneimine for highly selective $\mathrm{CO}_{2}$ detection, Sens. Actuators, B, 2016, 228, 551.

56 Y. Ma, H. Xu, Y. Zeng, C.-L. Ho, C.-H. Chui, Q. Zhao, W. Huang and W.-Y. Wong, A charged iridophosphor for time-resolved luminescent $\mathrm{CO}_{2}$ gas identification, J. Mater. Chem. C, 2015, 3, 66.

57 T. Tian, X. Chen, H. Li, Y. Wang, L. Guo and L. Jiang, Amidine-based fluorescent chemosensor with high applicability for detection of $\mathrm{CO}_{2}$ : A facile way to see $\mathrm{CO}_{2}$, Analyst, 2013, 138, 991.

58 Q. Xu, S. Lee, Y. Cho, M. H. Kim, J. Bouffard and J. Yoon, Polydiacetylene-Based Colorimetric and Fluorescent Chemosensor for the Detection of Carbon Dioxide, J. Am. Chem. Soc., 2013, 135, 17751.

59 S. Neethirajan, D. S. Jayas and S. Sadistap, Carbon Dioxide $\left(\mathrm{CO}_{2}\right)$ Sensors for the Agri-food Industry-A Review, Food Bioprocess Technol., 2009, 2, 115.

60 A. Star, T. R. Han, V. Joshi, J. C. P. Gabriel and G. Grüner, Nanoelectronic Carbon Dioxide Sensors, Adv. Mater., 2004, 16, 2049.

61 CrystalClear 2.0, Rigaku Corporation, Tokyo, Japan, 2016.

62 G. Sheldrick, A short history of SHELX, Acta Crystallogr., Sect. A: Found. Crystallogr., 2008, 64, 112.

63 O. V. Dolomanov, L. J. Bourhis, R. J. Gildea, J. A. K. Howard and H. Puschmann, OLEX2: a complete structure solution, refinement and analysis program, J. Appl. Crystallogr., 2009, 42, 339.

64 M. Nardelli, PARST95 - an update to PARST: a system of Fortran routines for calculating molecular structure parameters from the results of crystal structure analyses, J. Appl. Crystallogr., 1995, 28, 659. 
65 A. D. Becke, Density functional thermochemistry. III. The role of exact exchange, J. Chem. Phys., 1993, 98, 5648.

66 P. J. Hay and W. R. Wadt, Ab initio effective core potentials for molecular calculations. Potentials for the transition metal atoms Sc to $\mathrm{Hg}, J$. Chem. Phys., 1985, 82, 270.

67 P. J. Hay and W. R. Wadt, Ab initio effective core potentials for molecular calculations. Potentials for $\mathrm{K}$ to $\mathrm{Au}$ including the outermost core orbitals, J. Chem. Phys., 1985, 82, 299.

68 W. R. Wadt and P. J. Hay, Ab initio effective core potentials for molecular calculations. Potentials for main group elements Na to Bi, J. Chem. Phys., 1985, 82, 284.

69 Vibrationally-resolved electronic spectra in Gaussian 09, http://dreamslab.sns.it/pdf/vibronic_spectra_G09-A02.pdf.

70 J. Tomasi, B. Mennucci and R. Cammi, Quantum Mechanical Continuum Solvation Models, Chem. Rev., 2005, 105, 2999.

71 T. Yanai, D. P. Tew and N. C. Handy, A new hybrid exchange-correlation functional using the Coulombattenuating method (CAM-B3LYP), Chem. Phys. Lett., 2004, 393, 51.

72 A. Dreuw and M. Head-Gordon, Failure of Time-Dependent Density Functional Theory for Long-Range Charge-Transfer Excited States: The Zincbacteriochlorin-Bacteriochlorin and Bacteriochlorophyll-Spheroidene Complexes, J. Am. Chem. Soc., 2004, 126, 4007.

73 S. F. Boys and F. Bernardi, The calculation of small molecular interactions by the differences of separate total energies. Some procedures with reduced errors, Mol. Phys., 1970, 19, 553.

74 Y. Zhao and D. G. Truhlar, The M06 suite of density functionals for main group thermochemistry, thermochemical kinetics, noncovalent interactions, excited states, and transition elements: two new functionals and systematic testing of four M06-class functionals and 12 other functionals, Theor. Chem. Acc., 2008, 120, 215.

75 J. Schanda, Colourimetry: Understanding the CIE System, Wiley, Hoboken, New Jersey, 2007.

76 M. J. Frisch, G. W. Trucks, H. B. Schlegel, G. E. Scuseria, M. A. Robb, J. R. Cheeseman, G. Scalmani, V. Barone, B. Mennucci, G. A. Petersson, H. Nakatsuji, M. Caricato, X. Li, H. P. Hratchian, A. F. Izmaylov, J. Bloino, G. Zheng, J. L. Sonnenberg, M. Hada, M. Ehara, K. Toyota, R. Fukuda, J. Hasegawa, M. Ishida, T. Nakajima, Y. Honda, O. Kitao, H. Nakai, T. Vreven, J. A. Montgomery Jr, J. E. Peralta, F. Ogliaro, M. J. Bearpark, J. Heyd, E. N. Brothers, K. N. Kudin, V. N. Staroverov, R. Kobayashi, J. Normand,
K. Raghavachari, A. P. Rendell, J. C. Burant, S. S. Iyengar, J. Tomasi, M. Cossi, N. Rega, N. J. Millam, M. Klene, J. E. Knox, J. B. Cross, V. Bakken, C. Adamo, J. Jaramillo, R. Gomperts, R. E. Stratmann, O. Yazyev, A. J. Austin, R. Cammi, C. Pomelli, J. W. Ochterski, R. L. Martin, K. Morokuma, V. G. Zakrzewski, G. A. Voth, P. Salvador, J. J. Dannenberg, S. Dapprich, A. D. Daniels, Ö. Farkas, J. B. Foresman, J. V. Ortiz, J. Cioslowski and D. J. Fox, Gaussian 09, Revision E 01, Gaussian, Inc., Wallingford, CT, USA, 2009.

77 P. Alam, G. Kaur, S. Chakraborty, A. Roy Choudhury and I. R. Laskar, Aggregation induced phosphorescence active rollover iridium(III) complex as a multi-stimuli-responsive luminescence material, Dalton Trans., 2015, 44, 6581.

78 E. Baranoff, S. Fantacci, F. De Angelis, X. Zhang, R. Scopelliti, M. Grätzel and M. K. Nazeeruddin, Cyclometalated Iridium(III) Complexes Based on Phenyl-Imidazole Ligand, Inorg. Chem., 2011, 50, 451.

79 A. F. Rausch, H. H. H. Homeier and H. Yersin, in Photophysics of Organometallics, ed. A. J. Lees, Springer, Berlin, Heidelberg, 2010, p. 193.

80 Y. You and S. Y. Park, Inter-Ligand Energy Transfer and Related Emission Change in the Cyclometalated Heteroleptic Iridium Complex: Facile and Efficient Color Tuning over the Whole Visible Range by the Ancillary Ligand Structure, J. Am. Chem. Soc., 2005, 127, 12438.

81 J. Liang, Z. Chen, L. Xu, J. Wang, J. Yin, G.-A. Yu, Z.-N. Chen and S. H. Liu, Aggregation-induced emission-active gold(I) complexes with multi-stimuli luminescence switching, J. Mater. Chem. C, 2014, 2, 2243.

82 W. Z. Yuan, Y. Gong, S. Chen, X. Y. Shen, J. W. Y. Lam, P. Lu, Y. Lu, Z. Wang, R. Hu, N. Xie, H. S. Kwok, Y. Zhang, J. Z. Sun and B. Z. Tang, Efficient Solid Emitters with AggregationInduced Emission and Intramolecular Charge Transfer Characteristics: Molecular Design, Synthesis, Photophysical Behaviors, and OLED Application, Chem. Mater., 2012, 24, 1518.

83 N. L. C. Leung, N. Xie, W. Yuan, Y. Liu, Q. Wu, Q. Peng, Q. Miao, J. W. Y. Lam and B. Z. Tang, Restriction of Intramolecular Motions: The General Mechanism behind Aggregation-Induced Emission, Chem. - Eur. J., 2014, 20, 15349. 84 E. Quartapelle Procopio, M. Mauro, M. Panigati, D. Donghi, P. Mercandelli, A. Sironi, G. D’Alfonso and L. De Cola, Highly Emitting Concomitant Polymorphic Crystals of a Dinuclear Rhenium Complex, J. Am. Chem. Soc., 2010, 132, 14397. 